\title{
Increasing rewards and the impact on student behavior and school -wide discipline: A mixed methods study
}

Lorri Rumburg

West Virginia University

Follow this and additional works at: https://researchrepository.wvu.edu/etd

\section{Recommended Citation}

Rumburg, Lorri, "Increasing rewards and the impact on student behavior and school -wide discipline: A mixed methods study" (2009). Graduate Theses, Dissertations, and Problem Reports. 3511.

https://researchrepository.wvu.edu/etd/3511

This Dissertation is protected by copyright and/or related rights. It has been brought to you by the The Research Repository @ WVU with permission from the rights-holder(s). You are free to use this Dissertation in any way that is permitted by the copyright and related rights legislation that applies to your use. For other uses you must obtain permission from the rights-holder(s) directly, unless additional rights are indicated by a Creative Commons license in the record and/ or on the work itself. This Dissertation has been accepted for inclusion in WVU Graduate Theses, Dissertations, and Problem Reports collection by an authorized administrator of The Research Repository @ WVU.

For more information, please contact researchrepository@mail.wvu.edu. 
Increasing Rewards and the Impact on Student Behavior and School-wide Discipline: A Mixed Methods Study

Lorri Rumburg

\author{
Dissertation submitted to \\ the College of Human Resources and Education \\ at West Virginia University \\ in partial fulfillment of the requirements \\ for the degree of
}

Doctor of Education

in

Curriculum and Instruction

Joy Faini Saab, Ed. D., Chair Jane Cardi, Ed. D.

Phillip Ice, Ed. D.

Dennis Ruscello, Ph. D.

Allison Swan Dagen, Ed. D.

Department of Curriculum and Instruction

Morgantown, West Virginia

2009

Keywords: mixed method, behavior, rewards, positive behavior intervention, school

Copyright 2009 Lorri K. Rumburg 


\section{ABSTRACT \\ Increasing Rewards and the Impact on Student Behavior and School-wide Discipline: A Mixed Method Study}

\section{Lorri K. Rumburg}

This mixed method, embedded, correlational study's aim was to make explicit the relationships between changed procedures in one elementary school's PBIS universal program and student behavior as measured by office discipline referrals. A secondary aim was to use student and faculty responses on surveys to interpret participants' reactions to the increases in rewards, recognitions, and self-charting of daily behavior.

The type of data collected consisted of office discipline referrals generated over the course of the study year. Numerical data analysis also incorporated student totals for earned coupons, earned rewards and earned behavior points. Students surveys completed in October and May gauged student reactions to the PBIS changes. Faculty members and administrators completed an online survey in June.

Statistical results indicated limited correlation between student behavior and changes made in the universal program by increasing rewards and daily behavior charting. In contrast, survey results did reflect increased satisfaction with the changed universal PBIS program by faculty and students 


\section{Acknowledgements}

To start at the beginning of this journey, I would have to acknowledge the push and encouragement of my friend, Ann Getty, who thought our getting our doctorates together would be a grand thing. She was right. Thanks for your support, carpooling, coding, and sharing of resources over the past 35 months.

My thanks to the professors that instructed this "non-educator" in the culture, lingo, history, philosophy, complexities, and future of the profession, and expanded my vision of what I can bring to my own profession from this new fund of ideas. Like a kid in a candy store, the possibilities seem endless.

Without the participation, encouragement, and tolerance of the faculty, staff, and administration at my elementary school, this study would not have been possible. I owe them all a great debt. In particular, the PBIS team for the planning and implementing of the program changes investigated, and for leading their grade level teams in completion of all the data collection; Mr. John Logsdon, principal, for his support; Mrs. Val Llewellyn, PBIS coach, for her valuable insight and sharing of resources; Mrs. Kathy Strozykowski, teacher, for giving her time to code survey data; Mrs. Janet Mickey for being my coverage and stress absorber; and Mr. Scott Sisler, assistant principal, for his leadership in PBIS, his willingness to use the data generated to continue to shape the program, his expertise in generating spreadsheets, for his bringing me into the administrative world, and for quietly taking all the new "stuff" I was passing along and tucking it into a folder, as a reminder to me that everything can't happen at once.

My appreciation goes to Dr. Joy Faini Saab, as the kindest advisor and chair, for sending my research in a direction that sustained my interest and enthusiasm over the past year. I am grateful to my committee members who each played a role in making my research and my experience richer and whose input certainly resulted in a more polished and professional dissertation. Thanks to Dr. Dennis Ruscello, as my minor area mentor for requiring a review of speech pathology; Dr. Jane Cardi for her insight and suggestions to improve my prospectus; Dr. Phil Ice for overseeing my major comprehensive research, and just generally being an enabler and encourager during my course work; and to Dr. Allison Swan Dagen for her unfailingly positive and helpful comments.

I was blessed by my parents, family, friends, and colleagues that asked how things were going, and after listening to my litany gave me an encouraging word. Thanks to Dr. Kurt Lemmert and Dr. Lance Revennaugh for their statistical support. It was significant. 
Most importantly, to my husband, Russ, who is the only one that truly knows what this experience has been and what was required, and who kept our home together, and kept us both sane. Without you it would not have been possible. With love and thanks from the bottom of my heart.

"Not to know is bad. Not to want to know is worse. Not to hope is unthinkable. Not to care is unforgivable." -Nigerian saying 


\section{Table of Contents}

Chapter One

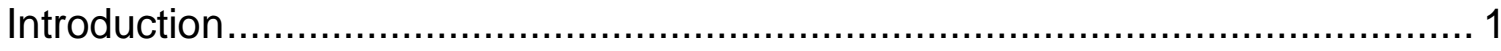

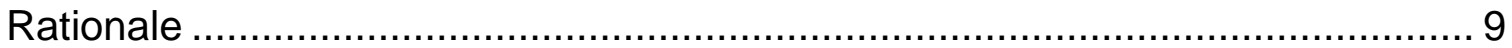

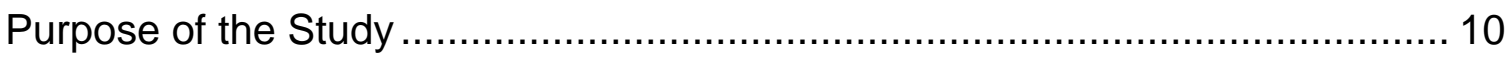

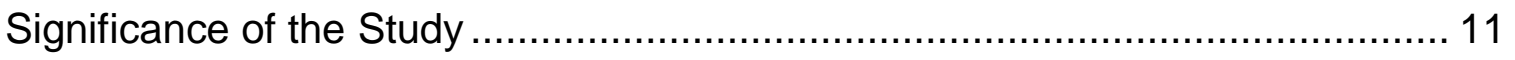

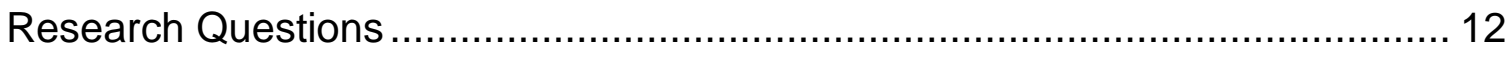

Definitions of Terms

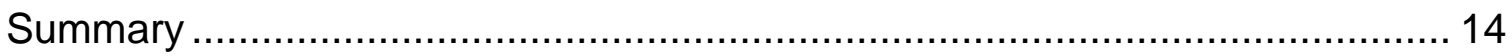

Chapter Two Literature Review

Positive Behavior Interventions and Supports ............................................. 15

Independent or Predictor Variable of Interest - Rewards ................................ 20

Independent or Predictor Variable of Interest - Self-monitoring

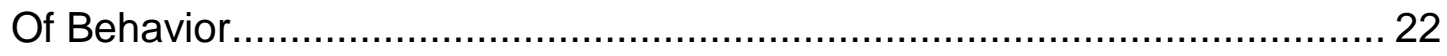

Dependent or Criterion Variable of Interest - Office Discipline

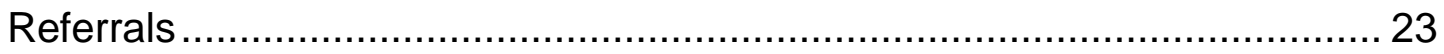

School-wide Information System (SWIS) .................................................. 26

Chapter Three Methodology

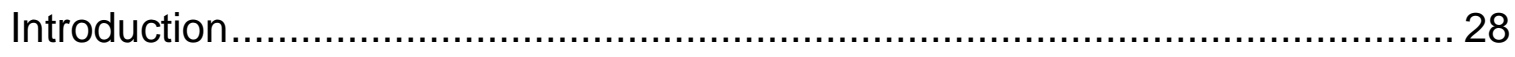

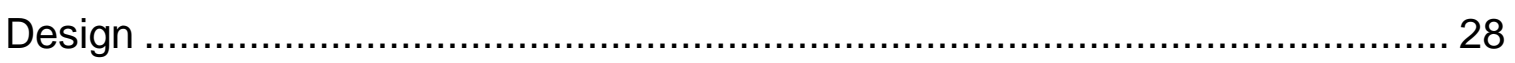

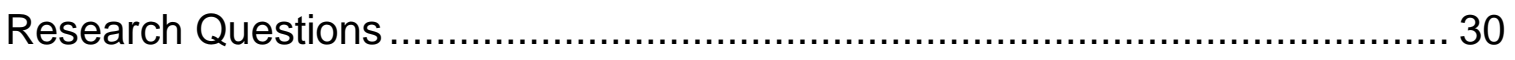

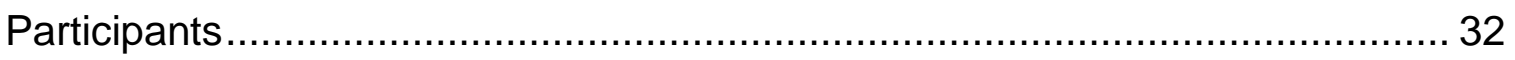

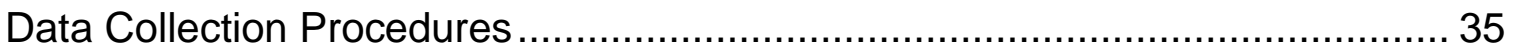

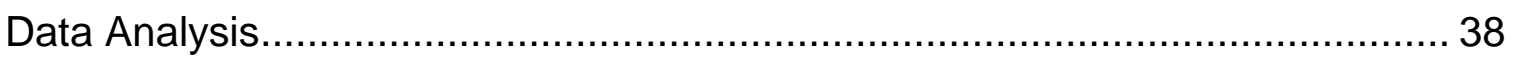

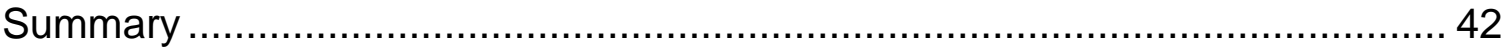


Chapter Four Results

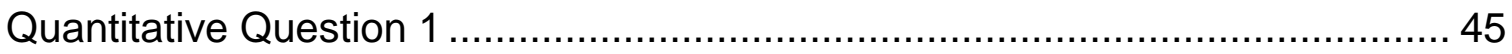

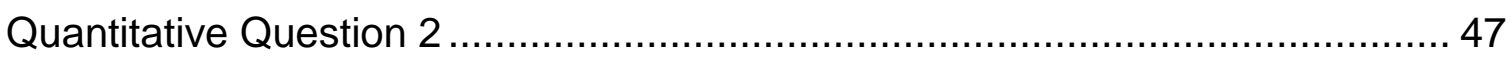

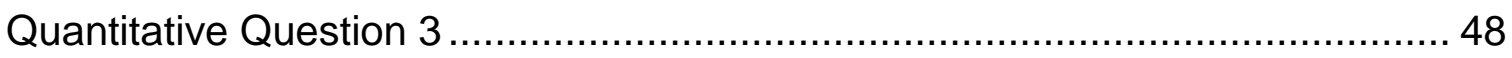

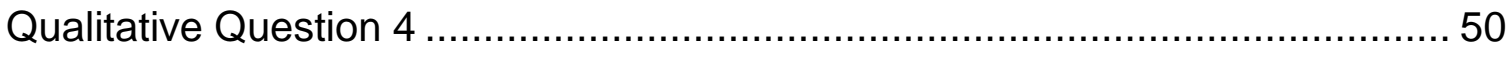

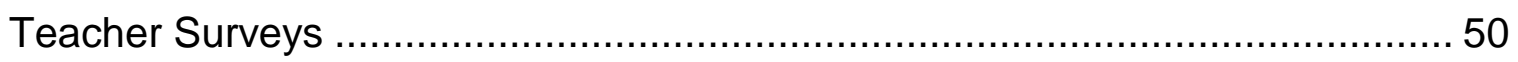

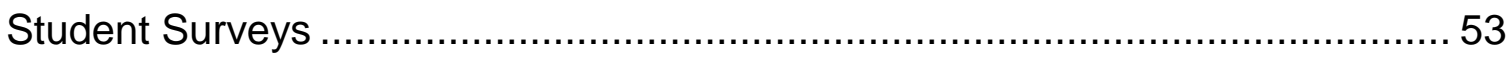

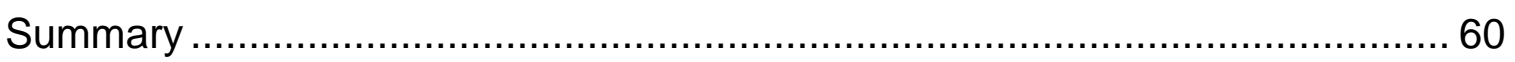

Chapter Five Findings, Conclusions, Discussion

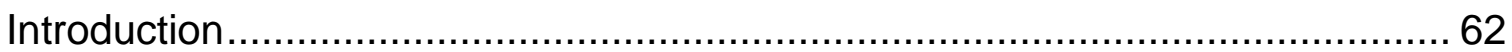

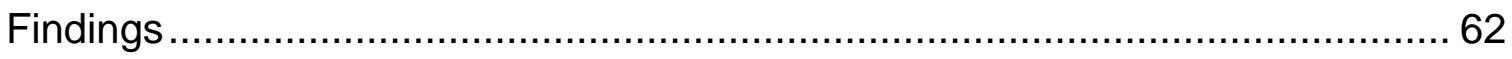

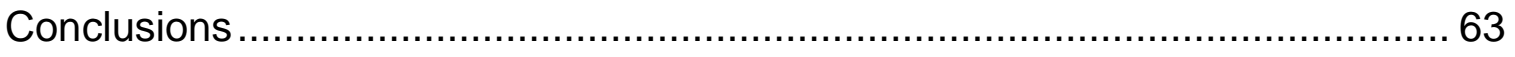

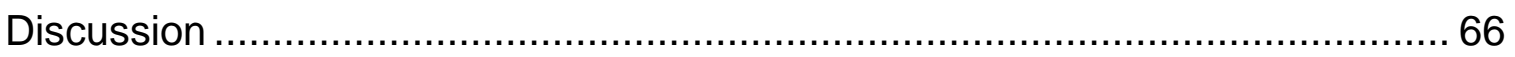

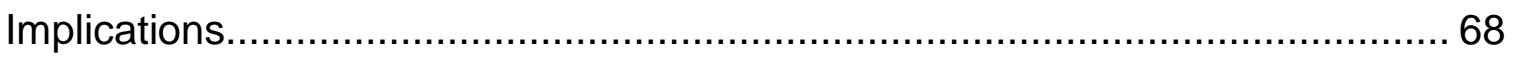

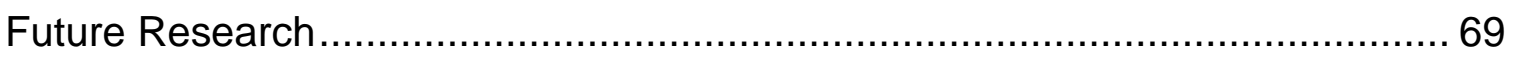

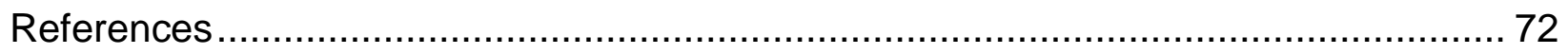

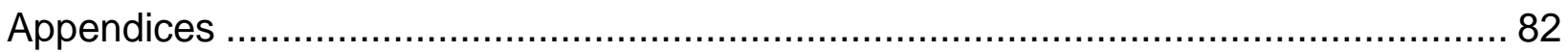

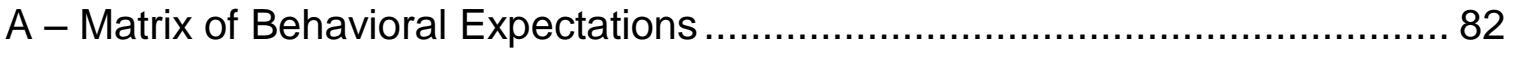

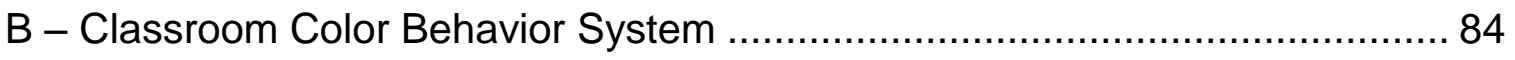

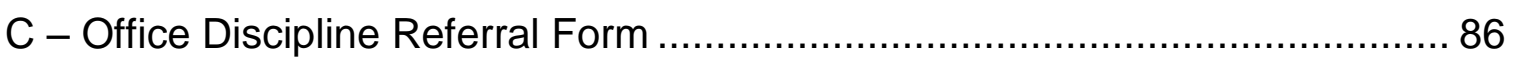

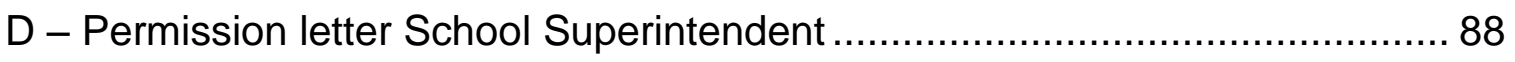

E - Permission letter School Principal ......................................................... 90

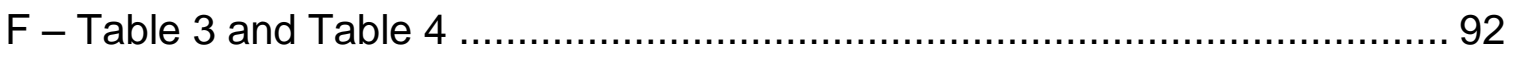

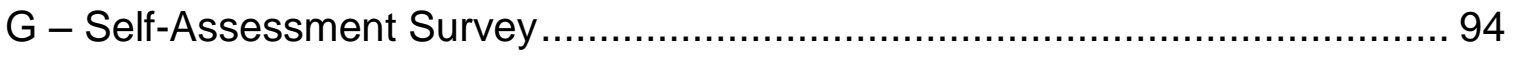

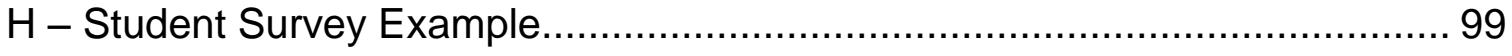




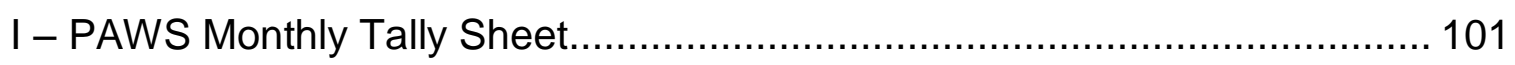

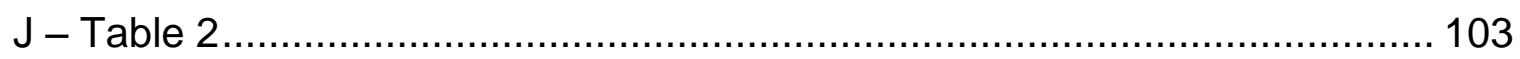




\section{List of Tables}

1 - Student Demographics at one elementary school over two academic years 32

2 - Comparative Office Discipline Referral for school year 2007-2008 (Key) and 2008-2009 (PAWS) 103

3 - Office Discipline Referrals by Number of Students ............................................. 93

4 - Office Discipline Referrals by Percentages of School Population..........................93

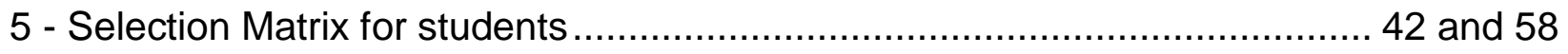

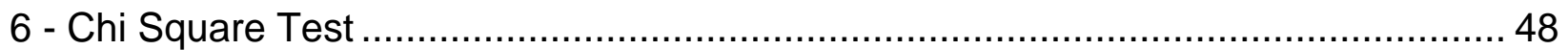

7 - Correlations of Independent and Dependent Variables........................................ 50

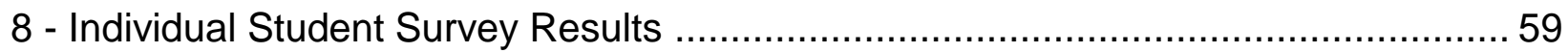

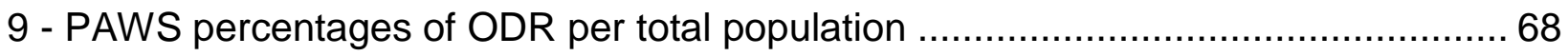




\section{List of Figures}

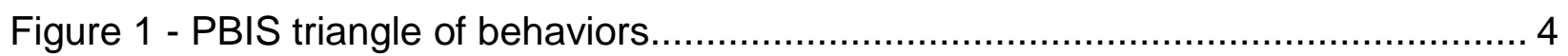

Figure 2 - Mixed method, correlational embedded research design........................... 30

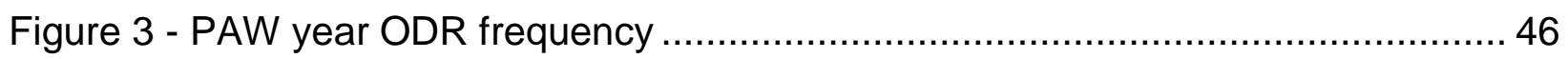

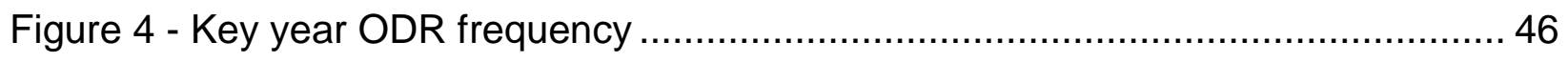

Figure 5 - Response Perceptions of PAWS strengths and weaknesses ...................... 51

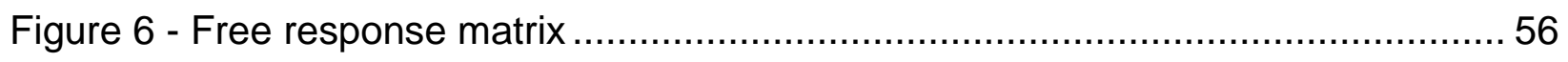

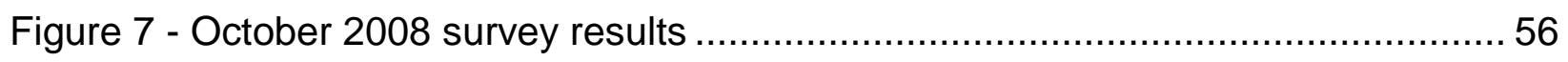

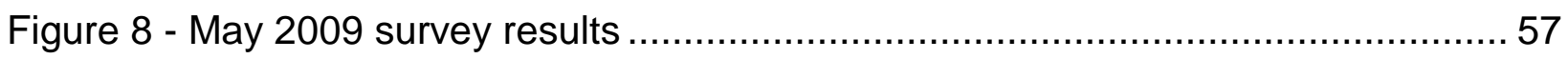




\section{CHAPTER ONE}

\section{INTRODUCTION}

Discipline in schools and the management of behaviors has its foundations in the first schools ever convened. From teachers who had the right to administer corporal punishment (Hyman \& Wise, 1979), to the exclusion of behaviorally, emotionally, and cognitively involved children from public schools (Special Education \& Rehabilitative Services, 2008), the movement to maintain an orderly school environment began to change in the early 1990's into one where instruction of positive behaviors is directly taught and rewarded, rather than using punishments and deterrents to maintain control.

In Mills v. Board of Education of the District of Columbia (1972) the court recognized that many children were being excluded entirely from education merely because they had been identified as having a behavior disorder. At that time, the view was that protections for those children should not prevent school officials from maintaining a safe and conducive learning environment for all children (Corr, 1998). The reauthorization of the Individuals with Disability Education Act (IDEA), in 1997 resulted in revisions to portions of the law, in particular, the additions of safeguards for children with emotional and behavioral problems. Concerned that these children were disproportionally being removed from regular educational opportunities, the 1997 IDEA and the 2004 IDEA revisions required that schools implement school-wide behavioral interventions in order to address the needs of these children in a manner consistent with their peers (Killu, Weber, Derby, \& Barretto, 2006).

The IDEA legislation brought into focus the concept of school-wide positive behavioral interventions which in turn were developed from previous public health 
initiatives, where the emphasis is on prevention through the training and the embedding of good health practices in daily life (Satcher, D., 1999). IDEA regulations also required functional behavioral assessments and behavioral intervention plans to be written for those children who did not respond to the school-wide program. Associated with No Child Left Behind legislation signed in January 2002, schools are required to have school safety plans addressing discipline, security prevention activities, student codes of conduct, and a crisis management plan (IDEA, 2004). All of these legislative acts brought to the forefront the need for better, more proactive and constructive means of promoting school discipline.

Positive behavior interventions were first developed to address self-injurious and aggressive behaviors exhibited by significantly disabled students (Durand \& Carr, 1985). A synthesis of applied behavioral analysis principles (Dunlap \& Horner, 2006) and the principles of inclusion and person centered values, Positive Behavioral Interventions and Supports (PBIS) evolved from a call to develop a similar, workable approach for the larger, typical school setting (Freeman, et al, 2006; Carr, Dunlap \& Horner, 2002; Larson, 1994).

Positive Behavior Interventions and Supports (PBIS) is a behavior management framework designed to decrease school-wide office discipline referrals. The foundation of PBIS is the prevention of behavior problems through the use of positive rewards, direct teaching of expected behavior, consistent application of behavior management principles by school staff, and the use of data to continuously adjust the application of these principles to accommodate the ever changing school environment (Carr, Dunlap, \& Horner, 2002). Positive rather than punitive measures that are proactive and 
preventive in nature have provided the structure for all PBIS school programs. The purpose of these measures is to address and prevent problem behaviors as early as possible (Sugai, Colvin, Hagan-Burke \& Lewis-Palmer, 2001).

Drawing on both systems theory and social learning theory, the developers of the PBIS framework provide training to schools that allow for individualized approaches that target each school's specific, self-defined needs (Bradshaw, Reinke, Brown, Bevans, Leaf, 2008; Carr, et al, 2002; Sugai \& Horner, 2002). A list of nine guiding principles emphasizes the importance of using data to guide and evaluate, of seeing discipline as a means of improving academics and behavior, and of using research-validated methods to sustain supports and prevent behaviors (Sugai, Colvin, Hagan-Burke, \& Lewis-Palmer, 2001). PBIS is not a prescriptive program, rather it provides a structure that individual schools adapt to the specific needs identified in their building and with their students (Scott, 2006). Exemplars are given for school teams to refer to in setting up the procedures for their own building, but no set of rigid requirements or PBIS expected procedures are disseminated.

The PBIS method anticipates that there will be three levels of behavioral need. The expectation is that there will be a percentage of students who do not respond to the universal application of rewards, teaching of specific positive behaviors, and a consistently administered framework (Walker, Hill, Horner, Sugai, Bullis, \& Sprague, 1996). At the school-wide level, "universal" or "primary supports" are put in place for the entire student body and are effective for $80 \%$ to $85 \%$ of students. The universal program's aim is to decrease the number of new cases of problem behaviors. "Secondary supports" are for the approximately $5 \%$ to $15 \%$ of at-risk students with a 
need for special interventions such as small group instruction in social skills, and checkin/check-out procedures (Hawkin, Pettersson, Mootz \& Anderson, 2005; Hawkin \& Horner, 2003). Secondary supports attempt to decrease the number of current students with two or more office discipline referrals. The third group is that $1 \%$ to $5 \%$ of students with high-risk behaviors requiring the "tertiary supports" of functional behavioral assessments, individualized behavior intervention plans, and possibly Individualized Education Plans (IEP) with behavior goals (Bradshaw, Reinke, Brown, Bevans, Leaf, 2008; Sugai, Colvin, Hagan-Burke, Lewis-Palmer, 2001). The tertiary supports hope to diffuse and decrease the complexity of behaviors in current students with six or more office referrals (Sugai et al, 2000). The PBIS model is illustrated by a triangle shape, with the levels representing the distribution of behaviors from the universal through the tertiary levels.

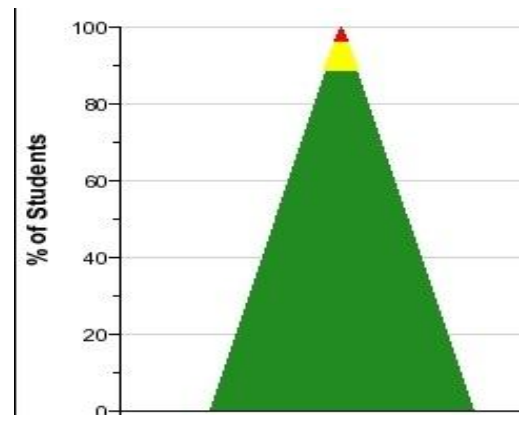

Figure 1: PBIS triangle of behaviors

Theoretic concepts from behavior modification and token economy systems, applied behavioral analysis, and systems theory suggest that increases in feedback, personal selection of reinforcement, and practical applications should result in both group and individual change (Ayllon \& Azrin, 1968; Dunlap \& Horner, 2006; Torbert, 1972). Token economies have been found to change behaviors secondary to 
reinforcements and self-selection for participation (Ayllon \& Azrin, 1968, O'Leary \& Drabman, 1971). While PBIS has a proven record of being effective in reducing referrals (Metzler, Biglan, Rusby, \& Sprague, 2001; Sprague, Walker, Golly, White, Myers, \& Shannon, 2001; Turnbull, Wilcox, Stowe, Raper \& Hedges, 2000; Taylor-Greene, et al, 1997), reducing suspensions (Horner, et al, 2008), and improving academics (Nelson, Martella \& Marchand-Martella, 2002), there are few studies ( Cuccaro \& Geitner, 2007) that look specifically at how schools structured their program in attempts to impact both total school-wide behavior and those of individuals along the continuum of general student body ( 0 - 1 office discipline referral), at-risk ( $2-5$ office discipline referrals), and high-risk students (6 or more office discipline referrals).

Maryland's initiative into positive behavioral supports began in 1998 with a series of trainings for interested schools, in conjunction with Sheppard-Pratt Health System and researchers from the University of Oregon's National Technical Assistance Center on Positive Behavior Interventions and Supports (Barrett, 2008). By 2002, the Johns Hopkins University Center for the Prevention of Youth Violence had joined in the training efforts which continued annually for three years and facilitated the training of coaches and school based PBIS teams (www.pbismaryland.org). As of the 2007 school year, PBIS had been adopted in six hundred and fifty (650) schools in the state of Maryland, and is in place in over 5,000 schools in all fifty states and the District of Columbia (National Technical Assistance Center).

Seven years ago, Positive Behavior Intervention and Support (PBIS) was introduced at the Maryland elementary school that is the subject of this study. PBIS was a new approach toward reducing the number of office discipline referrals. The year 
before the initial version of PBIS was introduced the office discipline referral data reflected four hundred twelve (412) referrals given to one hundred ten (110) students. The largest majority of these came from the classrooms; just over one half, at two hundred eighteen (218). By the end of the first year using PBIS, there were two hundred sixty eight (268) referrals given to seventy-six (76) students - a reduction in referrals of thirty-five percent (35\%) and a thirty-one percent (31\%) reduction in the number of students referred.

The theme chosen for the school community was "Key behaviors." Signs in school stated the Key concepts; students received Key coupons for demonstration of targeted Key behaviors, selections of "Key students" occurred weekly by draw from "Key boxes", hallway stop signs had the Key logo in place, even bathroom passes became wooden keys. The three targeted Key behaviors were "Be Responsible, Be Respectful, and Be Safe." The rationale for these three themes was based on information about the number of disciplinary referrals made in hallways and classrooms particularly.

From the fall of 2002 through the end of the 2008 school year, the PBIS program basically consisted of the Key components described above. Students were given paper coupons with the three target behaviors listed. Teachers checked observed behaviors and put the child's name on the back. Students then placed coupons in corresponding boxes in the office, and on Fridays, three names were drawn, one from each box. These were the "key students" for the week, their names were announced over the P.A. system, they wore a metal key on a lanyard around their necks for the week, had their photo placed on a bulletin board in the lobby area, and selected a small 
toy prize from the prize box in the assistant principal's office. In addition to this schoolwide PBIS program, within the classrooms, teachers utilized a four color system of blue, green, yellow, and red levels to give feedback to individuals about their daily ongoing behavior. This provided both positive (blue/green) and negative (yellow/red) commentary to children, but was not tied to the PBIS school-wide program.

Over the summer of 2008, the school PBIS team met to discuss how to revamp the PBIS program in order to increase the number of students recognized for positive behaviors, to refresh and inspire renewed interest in PBIS, to facilitate decreases in office discipline referrals and to reduce the increase in referrals seen each year in the spring months (Scott Sisler, Assistant Principal, personal communication, November 7, 2008). From those discussions a new approach was created, retaining the core features of the PBIS framework while introducing a new overall theme, a new target behavior, and new reward system. "Keys" became "PAWS" in honor of the school mascot. The target behaviors of "Be Safe," "Be Respectful" and "Be Responsible" were kept and "Be There" was added as an overall tie into the target behaviors. The "Be There" concept came from the Fish! Philosophy taught to all students by the guidance counselor (Charthouse, 2007). PAW coupons were still given out by teachers to students exhibiting the four target behaviors, but were placed in "CAT-Attitude" boxes in each classroom, rather than in the office. Weekly, one name was drawn from each of the seventeen classroom boxes, names were announced on the public address system, and those students ate on stage in the cafeteria at a special table and placed their names on the bulletin board located behind the table. These changes increased by 
over five and a half the number of times that students were recognized over the year (105 v. 595).

The other major feature changed was the direct relationship established between daily behavior and a monthly reward. Individual monthly calendars were kept in a folder. At the end of every day, students recorded their behavior "color" for that day. All faculty members receive in-servicing annually regarding a behavior matrix that describes expected behavior for Be Safe, Be Respectful, and Be Responsible in all school settings (see Appendix A). Typical expected student behavior resulted in a green designation; yellow may result from what are classified as Level 1 behaviors, while red indicated Level 2 or Level 3 behaviors (see Appendix B). Blue was reserved for exceptional positive student behavior. Green days earned one point, blue days earned two points, yellow and red days earned zero points. Each month the total number of points plus one point for every coupon students received were added and compared to a target for the month. Those students matching or exceeding the target received a token coin used to purchase a small item from the "Treasure Tower." In this way, nearly all students received a small reward monthly instead of only the three children lucky enough to have had their name drawn weekly from the "Key" boxes, as was the case in the past. The entire student body was rewarded with an end of the year carnival for reaching the attendance goal and at the carnival each child's annual sum result of all coupons and color points earned was used to "purchase" items from the PAW store.

My involvement on the school PBIS team led to the collection of school-wide, teacher administered surveys of student attitudes and perceptions of the Key framework for the purposes of action research to guide the new implementation processes. The 
Key survey was given the first day of the 2008-2009 school year, prior to a school-wide assembly explaining the new PAWS procedures. This open ended survey asked students in third through fifth grades to simply tell what they liked and what they did not like about the Key program. Fifty-seven percent (57\%) of the comments were positive, and forty-three percent were negative (43\%). By coding the results using inductive analysis, three themes were discovered. Students were highly concerned with how rewards and recognition were distributed, they were reflective and knowledgeable of the personal accountability of the target behaviors, and they were concerned with logistical issues involving particularly how the coupons were managed under the Keys protocol. The survey results were used to modify PAWS procedures to include the recognition of students over the public address system, and the privilege of eating at a special table in the cafeteria. That initial action research conducted by the school and the data collected piqued my interest in examining the potential benefits of the large increase in rewards and recognitions along with the tie to daily behavior charting and their impact on office discipline referrals. It made explicit the variables I wished to examine in this research study.

\section{Rationale}

This study built on the concept that universal systems of reward are effective motivators for positive behavior. Additionally, in the literature were two studies, (Durand \& Rost, 2005; Losel \& Beelmann, 2003) that called for specific information about the conditions where PBIS is both effective and less effective. Durand and Rost commented that the state of evidence recognizes that positive behavior supports work, but the conditions where it is less effective need clarification (p. 187). Losel and Beelmann's 
meta-analysis of eighty-four studies of social skills training on antisocial behavior found that programs that focused on the at-risk groups made a bigger impact than those that provided universal supports (p. 97). By looking at the effect of expanded universal practices on those students with secondary and tertiary needs, as well as the general student body, there was a potential to determine which school PBIS practices could positively impact behavior. Based on systems theory and its connection to learning experientially, it seemed reasonable to expect improved student behavior with increases in rewards. Systems theory states there is a positive correlation between feedback and behavior because the information received from its environment allows the system to adjust and adapt its behavior to reach a desired goal (Torbert, 1972, p. 8). By triangulating the literature regarding token economies, system theory, and PBIS effectiveness with the student reflections on past PBIS procedures, along with the indicators of office discipline referrals, there appeared sufficient basis both theoretically and practically to focus on school-wide and individual responses to the PBIS strategies introduced during the 2008-2009 school year.

\section{Purpose of the Study}

The overall purpose of the study was to assess the impact of changes made to an elementary school's Positive Behavior Interventions and Supports (PBIS) program on student office discipline referrals and student/faculty perceptions. The potential for any impact on student behavior was looked at through three factors. First, by looking at office discipline referrals, change across seven academic school years was compared to see if the increase in rewards and recognitions throughout the studied school year yielded improved behaviors. Second, examination was made of whether the factors of 
increased rewards/recognitions and personal daily self-monitoring of student behavior over a one year period resulted in change in individual students. Third, the variables introduced to the school community were compared to office discipline referrals to determine the extent of impact and what, if any, predictive value they had on behavior. For this study, student rewards were measured by numbers of coins earned and coupons received. Student behavior was measured by recording of office discipline referrals, and by the number of color points tallied.

Qualitative data from surveys completed by both students and faculty members were analyzed to gauge the reaction to and satisfaction with the new procedures implemented. Written student surveys completed in October and May were composed of both Likert scale items and open-ended statements (see Appendix H). In June, staff and administration completed a computer based survey, the Self-Assessment Survey, (see Appendix G) which utilized scaled questions regarding overall implementation of PBIS. It is used nationwide by PBIS schools and was accessed through http://www.pbissurveys.org/SelfAssessment/SelfAssessmentSurvey1.aspx.

\section{Significance of the Study}

This study examined the impact of changes on student behavior resulting from adjustments to universal level PBIS procedures made by one school, as measured by data from both individual (micro) and school-wide (macro) perspectives over the course of one year's data collection. The nature of these changes greatly increased the rewards and recognitions given and introduced the idea of student charting of daily behavior. While daily behavior charting has been used as an individual plan for students falling in the secondary or tertiary ranges (Chafouleas, Riley-Tillman, Sassu, 
LaFrance, \& Patwa, 2007; Riley-Tillman, Chafouleas, \& Briesch, 2007), nowhere were studies found that attempted this as a universal strategy. It was important to understand what if any impact these modifications had on the behavior of individual students with a history of office discipline referrals as well as the influence on the school as a whole. With that knowledge, PBIS procedures could be modified, or not, as warranted, and the value of universal procedures would be better understood.

\section{Research Questions}

The fundamental research question was to determine what effects the changes made to an elementary school's Positive Behavior Interventions and Supports (PBIS) program had on student behavior and participants' perceptions of the program.

Primary, Quantitative Questions

(1) Is there a relationship between the changes made in PBIS procedures (independent variable) and the numbers of problem behaviors (dependent variable) as measured by office discipline referrals over the 2007-2008 verses 2008-2009 school years for individual students with a history of office discipline referrals?

(2) Has significant change occurred in the total number of office discipline referrals by level $(0,1,2-5,6+)$ over the current school year as compared to each of the six previous years?

(3) How do the predictor variables (a., b., c.) relate to the number of office discipline referrals (criterion variable) for each student?

a. behavior points (monthly charts) 

b. token rewards (Treasure Tower coins)
c. teacher recognitions (coupons)

Secondary, Qualitative Research Question

(4) How do teachers and administrators, and students perceive the impact of the revised PBIS program on the school community?

\section{Definitions of Terms}

The following is a list of terms referenced throughout this research study for which a common understanding was necessary for clarity. Most terms were specific to the PBIS approach and may not be general knowledge for readers of this study.

At-risk students or secondary level students: those with $2-5$ office discipline referrals over the span of an academic year.

Behavior points: the points associated with a color which identifies a child's behavior at the end of each day. A green day is one point, blue days are two points, yellow and red days are zero points. Summed by students at the end of the month, August through May.

Expected behavior: positive actions that are specified for each of the chosen target behaviors throughout the school environment. Defined by the PBIS target behaviors of "Be Safe", "Be Responsible," "Be Respectful", and "Be There".

High-risk students or tertiary level students: those students with $6+$ office discipline referrals over the span of an academic year. 
Office discipline referral: a form completed by teachers that defines the problem behavior, indicates possible motivation, gives location, others involved, actions taken and the administrative decision made. This form is completed and sent home for parent signature. This form is also used in documentation of PBIS effectiveness.

Teacher recognitions: PAWS coupons given to students at random times by all staff and faculty as students are observed demonstrating one or more of the four PBIS target behaviors.

Token rewards: coins given to all students each month who accumulate the target number of points through daily behavior and coupons.

\section{Summary}

This chapter described the evolution of Positive Behavior Interventions and Supports (PBIS) from the initially identified need in the early 1990's through its implementation in the state of Maryland, and its application in the school under study. The purpose of the study was to examine the relationship that the significant modifications made in one school to the universal PBIS program had on student behaviors on a micro and macro level, as well as impact on student and faculty perceptions about the PBIS program. While the rationale for conducting the study was to validate previous research that investigated the use of positive reinforcement on behavior, the significance of the study was that the results reflected on how manipulation of the universal system directly affected student behavior. 


\section{CHAPTER TWO}

\section{LITERATURE REVIEW}

Positive Behavior Interventions and Supports (PBIS)

Applied behavior analysis (ABA) is one of the foundations upon which PBIS is supported. The "action-oriented field research" pioneered by Wolf and Risley, and reported beginning in 1968 with the inaugural publication of the Journal of Applied Behavior Analysis, blended the laboratory tested principles of behavior modification with a desire for practical and meaningful results in real world settings (Dunlap and Horner, 2006, p. 59). ABA concerns itself with looking at stimulus-response, but additionally, looks at the reinforcing consequences and so examines the situation where behavior occurs to determine appropriate solutions for both the individual and the social group as a whole (Dunlap \& Horner, 2006). The interest of researchers in ABA is to use positive strategies in order to reduce negative consequences or punishment and lead to improved quality of life (LaVigna \& Willis, 2005, p. 47).

Instrumental learning principles as derived from applied behavior analysis retain the concepts of positive reinforcement with stimulus control, but steps out of the laboratory to address strategies of instruction, manipulation of antecedent events, contingency management, use of functional analysis and assessments and the use of direct in-setting observations to solve problems of behavior in the places where they occur (Dunlap \& Horner, 2006, p. 59). These concepts are tied very closely to the main features of Positive Behavior Interventions and Supports as an applied science. In PBIS, the practical approach of looking at a problem behavior for its functional purpose 
to an individual, conducting environmental redesign so that antecedent conditions that reward and maintain the behavior are changed, and directly teaching social skills (Sugai \& Horner, 2000) clearly establish the link between this program to provide personcentered interventions with the behavior modification principles of the past.

In addition to $\mathrm{ABA}$, the theoretical basis for positive behavior interventions and supports comes from systems theory. To be significant, change must occur in the social system as well as the individual. Problem behaviors must be addressed by multiple interventions that address the context in which the behavior occurs as well as the behavior itself. System theory recognizes the manifold factors that influence individuals and the reactions they have to their surroundings. (Carr et al, 2002). I would like to add that another factor in the success of PBIS lies in the concept of experiential learning. The overlap between such learning and systems theory comes from the feedback received from the environment. Clearly in the framework of PBIS, feedback is a major component in the learning deemed necessary to impact change in individuals and the system itself.

While feedback can best be understood as information received by a person or system about its behavior, the assumption that feedback is readily recognized and applied toward the furtherance of positive goals is not always accurate. Torbert (1972) gives several examples of cases where feedback is distorted by those whom it is intended to benefit. He qualified feedback from a systems theory perspective as needing to be "shared, public, immediate, first-hand, non-conceptualized, selfacknowledged, authenticity-enhanced, non-evaluative, descriptive and non-controlling" (p. 11). In order for a system to accept and respond to feedback, it requires defined 
goals so that it is possible to recognize movement toward that goal. This goal directed behavior is termed first-order feedback. Using feedback to guide systems toward necessary change in order to meet goals is termed "learning" or second-order feedback. The third-order of feedback attends to system - environment interactions to stay focused on the overall "purpose and integrity of the system" (Torbert, 1972, p. 14). The originator of General System Theory, Kurt Ludwig von Bertalanffy, proposed a view of individuals not as stimulus-response organisms, but as active personalities seeking purpose, adapting to change, and striving to reach goals. System thinking looks holistically and sees problems as part of a system best understood in relationship to the whole (Ludwig von Bertalanffy, n.d.). Conceptually then, PBIS uses a framework of system theory and applied behavior analysis, where the individual and the environment interact to positively impact children so they are ready to succeed in adulthood.

In 1996, a group of researchers at the University of Oregon, led by Hill M. Walker, took on the task of addressing what then Surgeon General C. Everett Koop declared was the number one public health problem facing the nation. Dr. Koop in 1992 called for help in combating interpersonal violence. Previous approaches were reactive and punitive. Walker et al (1996) co-opted the US Public Health stance of viewing problems in two dimensions; one, the identification of and targeting the reduction of risk factors; and two, the development of protective strategies to offset the risk. This vision, integrated with the US Public Health classification system of primary, secondary and tertiary levels of need (Larson, 1994; Biglan, 1995) led to the formulation of Positive Behavior Supports and Interventions as a way for public school systems to provide effective interventions at an early age (Walker et al, 1996; Sprague, Walker, Golly, 
White, Myers \& Shannon, 2001). Walker and his colleagues (1996) called upon schools to take a proactive position through school-wide interventions, screening students on school entrance, partnering with families and community resources, and eliminating of exclusionary practices such as expulsion and suspension. They also advocated returning to a continuum of student service provision options rather than pursuing the push for full inclusion in typical education.

In this initial article, the three classifications of need were delineated. As per the public health system, the primary level is where preventive measures are the focus. Walker et al (1996) posit that this would encompass $80 \%$ to $85 \%$ of a student body. The secondary level is where the focus is to reduce emerging problems, accounting for $5 \%$ to $15 \%$ of students, and the tertiary level is where the hope is to reduce or reverse ongoing damage for that $1 \%$ to $5 \%$ of students in the high-risk group. Suggestions for treatment at each level were given including school-wide instruction in anger management and conflict management, academic supports and finally interagency cooperation for comprehensive help for those with persistent antisocial and delinquent behavior patterns.

Sugai et al (2000) and others evidenced legislature such as the 1997 amendments to IDEA (Turnbull, Wilcox, Stowe, Raper \& Hedges, 2000; Missouri State Dept. , 2001), Goals 2000, and Improving America's Schools Act as proof that society expects schools to focus on establishing lifestyle changes so that problem behaviors become inefficient and irrelevant. No Child Left Behind legislature signed in January 2002 requires schools to have a school safety plan including discipline, security, student codes of conduct, crisis management, and prevention activities (Bradshaw et al, 2008). 
Person-centered values encourage involvement of the student in deciding what to change with self-determination of desirable, practical and effective outcomes (Carr et al, 2002). School-wide positive behavioral support sees prevention and direct teaching of desirable social skills as the primary tool for producing a successful school culture (Freeman, 2006).

Application of PBIS principles to a school setting requires the structured implementation of several components. Training materials developed by Sugai, Colvin, Hagan-Burke, \& Lewis-Palmer (2001) delineated nine guiding principles needed for the successful functioning of PBIS in a school. These are:

1. Use data to guide decision making

2. Establish school discipline as instrument for academic and behavior success

3. Utilize research-validated approaches

4. Emphasize an instructional approach to behavior management

5. Emphasize prevention

6. Build and sustain continuum of behavior support

7. Consider and implement school-wide program for all students, all staff, and all settings

8. Evaluate continuously

9. Coordinate efforts with a school-wide leadership team.

(Sugai, Colvin, Hagan-Burke, \& Lewis-Palmer, 2001, P. 1). 
In the state of Maryland, the PBIS initiative began in 1998 with a collaboration between the Maryland State Department of Education (MSDE) and Sheppard Pratt Health System (SPHS) to stabilize schools through the implementation of universal procedures, provision of money to train staff to work with at risk students and placement of mental health community resources in public schools with the high-risk students. July 1999, Dr. George Sugai from the University of Oregon was guest speaker at the first Maryland PBIS workshop. Summer institutes were held the following four years and by the fall of $2005,33 \%$ of Maryland schools were using PBIS strategies and all twentyfour school districts were participating. (Barrett, 2008)

PBIS implementation expects that each school will determine three to five school-wide behavioral expectations that will be actively and directly taught to all students. A system for monitoring and acknowledging student compliance must be developed, and non-compliance will have a consistent continuum of consequences in place. In addition, data about student behavior is to be collected regularly and used by the school PBIS team to direct teacher and administration responses to student behavior. For PBIS to be successful there must be active leadership from a school administrator who establishes the school team, serves on the team and is available to implement behavior support. At the district level, there must be support for ongoing training, along with expectations for data collection and for schools to be safe (Horner et al, 2004).

Independent or Predictor Variable of Interest - Rewards

While PBIS is a "behaviorally based systems approach" (Sugai et al, 2000, p. 106), the premise for the framework of rewards comes from behavior modification and 
token economy practices. Where pure stimulus-response conditioning requires complete control of the environment, rewards, and desired goals by the experimenter, the context in a school is less well regulated. The principle remains, however, that observable behavior is the response and the stimuli are the specifically taught expectations and associated reinforcement of student production of said expectations.

An early example of the application of a token economy into a complex social system occurred at a state mental facility in 1968. Using operant reinforcement theory, Ayllon and Azrin (1968) developed a reinforcement and extinction procedure to impact a variety of behaviors demonstrated by vastly differing personalities in multiple settings and across multiple timeframes. The researchers directly admitted that manipulation of environmental consequences was selected because of the ease of measuring and controlling these consequences. Modifying behavior by appealing to cognitive perceptions was too uncertain (p. 8).

Extreme behaviors seen in the mental institution required looking at multiple potential reinforcements, but the focus was on establishing positive functional behaviors. Negative or punitive consequences were not permitted. Target behaviors were selected, ward staff were trained in administering tokens, and charting of patient response to the system led to modifications on an ongoing basis as evidence decreed. The results were that target behaviors continued as long as the tokens were given, but the positive behaviors ceased with the removal of the reward. An additional finding was that tokens needed to be given for specific behaviors, rather than unspecified acts ( $p$. 188). While arguably quite different in circumstance from the typical PBIS school, many of the same principles can be seen at work in the PBIS framework. 
In a study of reinforcement (Sharpley, 1988) its effectiveness was confirmed, but only in the conditions where reward were administered directly and contingently upon specific behavior. Those rewards that were given but not contingent on specific behavior had no effect. A second study involving seven hundred students in a $\mathrm{K}-5$ elementary school had slightly different results. In this case, rewards for "good behavior" were given at random and resulted in positive changes in a school cafeteria. Adding social honors also increased positive behaviors. (Fabiano, Pelham, Karmazin, Kreher, Panahon, \& Carlson, 2008).

The reward program in place in this study is a combination of both intermittent and contingent reinforcement. The giving of coupons by faculty and staff are random rewards while the Treasure Tower coins are contingent upon the accumulation of a specific number of behavior points. Social reinforcements in the form of student names announced on Monday morning announcements, eating at a special lunch table, and placing names on the stage bulletin board were added as a result of student comments about desiring recognition, stated on the beginning of the school year surveys. The studies cited previously suggested that the increased reward system should have had an impact on student behavior.

Independent or Predictor Variable of Interest - Self-monitoring of behavior

Long and Edwards (1994) reported results using a daily behavior report card to communicate to parents about the daily performance of their child in school. No specific research was conducted, but comments about possible forms to use and application by classroom teachers were covered. A series of studies from 2002 to 2008 was more systematic in the investigation of daily behavior report cards. Chafouleas, Riley-Tillman, 
Sassu, LaFrance, and Patwa (2007) compared the teacher use of a daily behavior report card (DBRC) using a Likert scale rating of a specific target behavior to an external observer's completion of the same tool as well as systematic direct observation. Enough consistency was evidenced for the researchers to conclude that this system of behavior monitoring was acceptable for "low-stakes" interventions (p. 35). Further work by Riley-Tillman, Chafouleas, and Briesch (2007) confirmed the usefulness of daily behavior report cards for providing data on response to intervention (RTI). These studies, and others that report on using some form of charting of student behavior (Hawkin \& Johnston, 2007; Hawkin \& Horner, 2003) all apply the principle of using a visual/numeric rating that children see and share with another person (typically a school designee and/or parent) by those children who were not responding to the universal levels of the school-wide interventions. I have not been able to locate research where a behavior monitoring system is applied school-wide with daily selfrecording such as is being implemented in the subject school. Thus my interest in the impact of this example of a system theory approach to providing feedback that is "immediate, first-hand, self-acknowledged, descriptive, and non-controlling".

Dependent or criterion variable of interest - office discipline referrals

With PBIS being put in place in thousands of schools across the country, the question became how to evaluate the effectiveness of the interventions. Training materials developed at the University of Oregon illustrate by using a triangle for differentiating the three levels of support provided to students. At the base of the pyramid are approximately $80 \%$ of students who need only universal support. Near the top, in yellow, are the $10 \%$ to $15 \%$ who are at-risk and need secondary supports. At the 
tip of the triangle are those $5 \%$ of students who exhibit high-risk behaviors and require tertiary or intense, individual support (Sugai, Horner, Lewis-Palmer, Hagan-Burke, Todd \& Tobin, 2001).

Several studies have addressed the issue of the validity of using office discipline referrals (ODR) as a measure of behavior change. Sprague, Sugai, Horner, and Walker in 1999 reported analysis from several schools using ORD and found that the use of ODR's was a simple method of analyzing data to provide direction in assessing impact of PBIS and in planning needed interventions.

In Metzler, Biglan, Rusby and Sprague's study (2001), two communities' middle schools were studied using an $A B$ design over a two year period. Baseline data of student surveys and monthly discipline referrals were collected for the first year. The Effective Behavior Supports (EBS) program was put in place in one school only for the second year. A comparison between the two buildings was made using the ODR data, student survey reports of teacher praise, and numerical tallies of reward tokens. There was a significant reduction in referrals for those students with a history of ten or more referrals in the EBS school. These authors were concerned with the validity of using discipline referrals, but cited a study by Wright and Dusek (1998) that found variation in the rating of behavior by office referrals between schools, but a tendency for referrals to be consistent within a school.

The utility of office discipline referrals was discussed in a study by Clonan, McDougal, Clark and Davison (2007) who provided an example of how school psychologists could use ODR's to guide decisions about interventions for students. The standardized format, the usually timely manner in which ODR's are reported and the 
function as a source of teacher generated information about a particular child and situation were practical reasons given for the use of ODR for intervention-oriented problem solving.

The most comprehensive look at the use of office discipline referrals as evaluative information came from a review by Irvin, Tobin, Sprague, Sugai, and Vincent in 2004. They used Messick's "Unified Approach to Construct Validity" protocol which he developed in 1988 for the evaluation of empirical measures for validity. Responding positively to his four questions provides validation not only through justifying evidence but also requires determining the value implications and social consequences of using said measures (p.134). In other words, it looked at the use of office discipline referrals from the perspective of the whole system. The authors' survey of forty-four articles resulted in positive validation of ODR's as indices of school climate in a positively correlated fashion, where higher discipline referrals reflected higher levels of poor school climate. Twenty-one studies were reviewed for validation of the use of ODR as a measurement of the effect of interventions. Several of the studies described schoolwide programs such as Project ACHIEVE, Character Counts!, Positive Action, and School-wide Behavior Intervention in forty-two different schools. In all but one school, the number of discipline referrals decreased following implementation of the behavior intervention programs. The summary findings of this meta-analysis were that office discipline referrals are a valid way to assess program success on a school-wide basis. The data generated provides a means to problem-solve for specific school concerns and can be used to evaluate change within a school in terms of climate and also intervention effectiveness. Because referrals represent a sequence of events beginning 
with the student's behavior, the referring teacher's reaction, and the administrative response, concerns have been raised by Nelson, Gonzalez, Epstein, and Benner (2003) about the possibility of false positives (referring unnecessarily) and false negatives (not referring when needed, especially for internalizing students). Irvin et al (2004) responded that while these are serious issues on an individual basis, looking at ODR's on a school-wide scale remained validated based on their findings using Messick's protocol.

School-Wide Information System (SWIS)

To facilitate the collection of office referral data in a convenient and easily managed way, University of Oregon researchers (May et al, 2003) developed a webbased system that produces both histograms and frequency distribution tables of referral data for individual schools. The data can generate reports on numbers of total referrals by month, by location within the building, by type of problem behavior, by time of day, by student and by teacher. The SWIS program's intent is to facilitate use of data by making the administrative effort needed to enter data minimal.

In the SWIS reporting system, referrals are grouped by categories that are related to the three levels of the triangle: universal, secondary, and tertiary. Those students with zero to one referral in a year are in the universal group. Referrals of two to five over a year move students into the secondary tier. The highest need group, or tertiary, has six or more office discipline referrals (May et al, 2003).

Irvin et al (2006) looked at the use of SWIS data through a logic model based on four hypotheses. $H_{1}$ was that school personnel use the data about ODR to make decisions about school-wide and individual interventions. $\mathrm{H}_{2}$ was that convenient 
summaries of data supported this process. $\mathrm{H}_{3}$ was that data based decisions result in actual implementation of interventions, and $\mathrm{H}_{4}$ was that implementation results in positive outcomes which will be reflected in ODR data. The authors found that $62 \%$ to $77 \%$ of elementary schools were using SWIS to determine behavior problems early in the school year, for recognition of specific problem behaviors, and to plan ways to solve problems within the PBIS framework. Less frequently did schools make use of SWIS data to monitor the effectiveness of interventions. The Irvin, et al (2006) study reported findings only for the first two hypotheses. In the study reported here, the third and fourth hypotheses were addressed. The school implemented changes in the schoolwide intervention based on the previous year's data, and positive results based on office discipline referrals were the hoped for outcome. 


\section{CHAPTER THREE}

\section{METHODOLOGY}

Introduction

The purpose of this study was to determine the impact of changes made to an elementary school's Positive Behavior Interventions and Supports (PBIS) program on both the macro (total school) and micro (individual students) levels. Specifically, the study investigated how two new ways of rewarding and recognizing students, along with daily self-charting of behavior by students impacted their behavior. By looking at the relationships of the variables of more student recognition and personal behavior charting on school-wide and individual behavior, this study aimed to provide insight into possible methods that could influence the number of office discipline referrals made during a school year. This section describes the design, the research questions, the participants, the measures planned for data generation, the collection procedures and data analysis processes.

\section{Design}

This study took place at one elementary school located in a mixed residential and commercial area in a small city (population 21,518 , U.S. 2000 census) in a rural Maryland county. The study looked specifically at data collected during the 2007-2008 and 2008-2009 school years relative to a school-wide behavior program. All data included in this study were extant data collected by the school and were examined at the end of the 2008-2009 school year. 
A correlational, concurrent, embedded mixed method design was chosen to examine this year-long, school initiated project. By acknowledging my pragmatic worldview, which is typically associated with mixed methods research (Creswell \& Plano Clark, 2007, p. 23), the use of a correlational study method was complimentary to that view of research since it was problem centered, and real-world practice oriented (Creswell \& Plano Clark, 2007). The correlational methodology observed without manipulation of the variables of interest: student behavior (coupons), administration of rewards (coins), student charting of behaviors (points) and occurrences of office discipline referrals (ODRs). This permitted the determination of possible relationships between the variables as they occurred in a real world condition (Cozby, 1989; Bordens \& Abbott, 2002). This study used both quantitative and qualitative data that were collected concurrently, or simultaneously, throughout the study. The weighting of the use of the qualitative and quantitative again was influenced by a pragmatic worldview in that the data that best answered the overall research question was weighted more heavily. The qualitative data was embedded in the quantitative data and was used to expand the findings of the quantitative measures.

Following the recommendations of Creswell and Plano Clark (2007, p. 68) the design model below (Figure 2) characterizes the current study. As they suggested (2007, p. 64), the use of uppercase letters and lower case letters illuminates the precedence given the data during interpretation. 


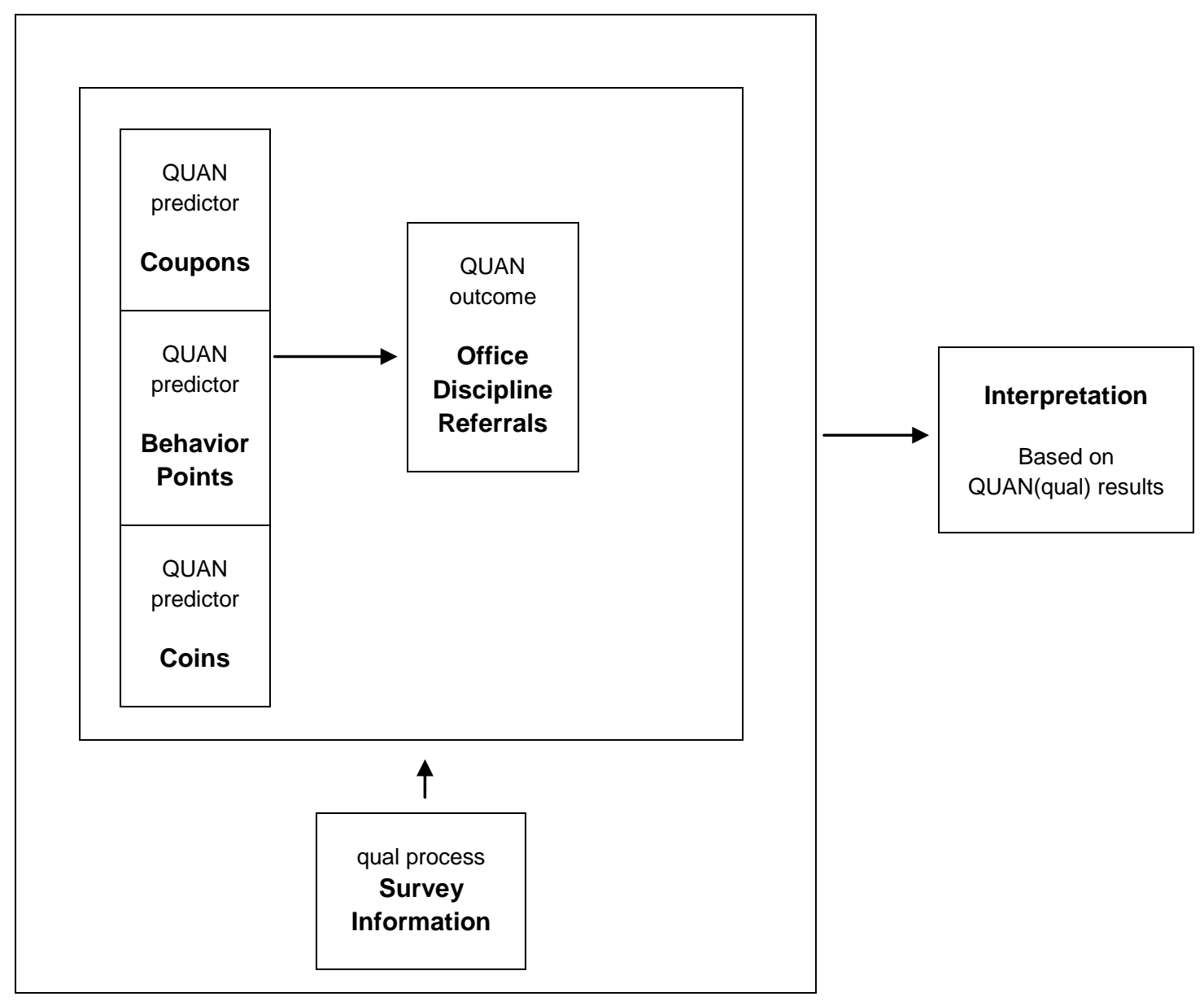

Figure 2: Mixed method, correlational, embedded research design

\section{Research Questions}

By using a correlational, mixed method design, this study allowed for the examination of both quantitative analysis of numerical indicators of student actions and recognitions along with self-reported perceptions of students and teachers about the new methods instituted at the beginning of the 2008-2009 school year.

The questions of interest regard how students reacted to the changed PBIS procedures, both on an individual basis and as a social system. This study used three statistical processes and archival school surveys of student and teacher/faculty 
perceptions of the program to evaluate the research questions (Bordens \& Abbott, 2002; Gravetter \& Wallnau, 2007).

Primary Quantitative Questions:

This study used a Wilcoxon Signed Ranks test to answer the research question:

(1) Is there a relationship between the changes made in PBIS procedures (independent variable) and the numbers of problem behaviors (dependent variable) as measured by office discipline referrals over the 2007-2008 verses 2008-2009 school years for individual students with a history of office discipline referrals?

A chi-square test for independence answered the research question:

(2) Has significant change occurred in the total number of office discipline referrals by level $(0,1,2-5,6+)$ over the $2008-2009$ school year as compared to each of the six previous years?

A coefficient of determination $\left(r^{2}\right)$ and linear regression equations answered the research question:

(3) How do the predictor variables (a., b., c.) relate to the number of office discipline referrals (criterion variable) for each student?
a. behavior points (monthly charts)
b. token rewards (Treasure Tower coins)
c. teacher recognitions (coupons) 
Secondary, Qualitative Research Question

(4) How do teachers and administrators, and students perceive the impact of the revised PBIS program on themselves and the school community?

\section{Participants}

Students involved in the PBIS program and whose data measures were observed during this study attended the Pre-K through fifth grade elementary school for the 2007-2008 and 2008-2009 school years. During the study year (2008-2009), students were responsible on a monthly basis for calculating their point totals of coupons and daily behavior, as well as completing two surveys about the PBIS programming. Comparisons between the student populations for the two years indicated stability in the characteristics of the students (see Table 1).

Table 1 Student Demographics at One Elementary School Over Two Academic Years

\begin{tabular}{|c|c|c|c|c|c|c|c|c|c|}
\hline $\begin{array}{c}\text { Academic } \\
\text { Year }\end{array}$ & $\begin{array}{c}\text { Total } \\
\text { Student } \\
\text { Population }\end{array}$ & $\begin{array}{c}\% \\
\text { Male }\end{array}$ & $\begin{array}{c}\% \\
\text { Female }\end{array}$ & $\begin{array}{c}\text { Teacher: } \\
\text { Student } \\
\text { Ratio }\end{array}$ & $\begin{array}{c}\% \\
\text { FARMS }\end{array}$ & $\begin{array}{c}\% \\
\text { IEP }\end{array}$ & $\begin{array}{c}\text { Single } \\
\text { Parent } \\
\text { Homes }\end{array}$ & $\begin{array}{c}\text { Mobility } \\
\text { Rate }\end{array}$ & Attendance \\
\hline $\begin{array}{l}2007- \\
2008\end{array}$ & 316 & $54.70 \%$ & $45.30 \%$ & $01: 17.6$ & $58.50 \%$ & $14.20 \%$ & $35 \%$ & $63 \%$ & $95.80 \%$ \\
\hline $\begin{array}{c}2008- \\
2009\end{array}$ & 302 & $54.50 \%$ & $45.50 \%$ & $01: 17.7$ & $61 \%$ & $16 \%$ & $34 \%$ & $62 \%$ & $95.60 \%$ \\
\hline
\end{tabular}

Of note were the numbers of students from single parent homes attending this particular school. While the school had $34 \%$ and $35 \%$, by year respectively, of the student body living in a single parent home, comparatively, its home city, as a whole, had $8.4 \%$ of school-aged children living in a female, head of household single parent 
home (U.S. Census, 2000). The other demographic worth mentioning is the mobility rate in the school population over the course of a year's time. Over the two years in question, the school had an average $62.5 \%$ turnover (sum of new enrollments and withdrawals divided by total fall enrollment). In contrast, the Department of Defense (D.O.D.) characterized their schools as being in "constant flux" (p. 165) with a $37 \%$ average turnover rate in D.O.D. schools run for children of military personnel (Smrekar \& Owns, 2003).

Staff at the study school came from all across this rural county, from a neighboring county, and from nearby Pennsylvania and West Virginia. Over both school years, one hundred percent (100\%) of the faculty was highly qualified to teach in their assigned grade level or subject area by the standards established in No Child Left Behind legislature. Faculty and staff at the school participated in the PBIS program at all levels. A teacher from every grade level along with instructional assistants, guidance counselor, and this researcher were members of the PBIS team. Within each classroom, the teachers taught the lessons that were developed to explicitly teach the target behaviors of "Be Safe," "Be Respectful," and "Be Responsible." They maintained the classroom box for coupons, drew names weekly and sent them to the office, distributed coupons to students to reinforce positive behavior, and also utilized the color coded behavior system. Teachers also structured their day so that time was available each afternoon for recording the daily color, and monthly for the computation of monthly point totals. Students were given coins as earned and taken to the Treasure Tower by staff, as well. Beyond the daily administration of the PBIS program and in planned booster activities, the faculty and staff completed several informal surveys throughout 
the year aimed at providing information for ongoing action research during the 20082009 school year. Additionally, faculty and staff completed an online survey titled the PBS Self-Assessment Survey, accessed online through the Maryland PBIS web site, as recommended by PBIS procedures.

Administration support occurred through the provision of materials and supplies necessary to maintain the reward system. The assistant principal served as the PBIS team chairman. Office discipline referrals (ODR) were primarily sent to and dealt with by the assistant principal, as guided by both school and county generated discipline policies. Each office discipline referral generated a sequence of events, culminating in the recording of information onto an ODR form (see Appendix C) about the day, time, location, student, referring staff, nature of the problem behavior, others involved, previous teacher actions taken and finally the administrative decision taken Information from the ODR form was entered into the data collection system (SWIS) mainly by this researcher, along with the assistant principal and the school's PBIS coach.

\section{Data Collection Procedures}

I was given verbal and written permission to conduct this research from both $\mathrm{Dr}$. William AuMiller, superintendent of Allegany County Public Schools, and from Mr. John Logsdon, school principal (see Appendices D and E). Permission to access student records and faculty survey results for the purposes of this study was obtained from the West Virginia University Institutional Review Board (IRB) for the Protection of Human Subjects prior to reviewing data for this study. I was also authorized by the school's assistant principal, Mr. Scott Sisler, to access the School-Wide Information System (SWIS) account established for this school. The School-Wide Information System 
(SWIS) data system (May et. al, 2008) is a computer based collection system where office discipline referrals are recorded by day, time, place, student, type of behavior, referring staff member, and administrative decision. SWIS generates frequency distributions specific to the above descriptors. This makes it possible to see the number of office discipline referrals by student and for the school at large. The individual students are assigned a random six to eight digit code by the SWIS computer program so that there is no identifying information. This account has controlled access, with only the administrators, myself, and the PBIS coach for the school able to log onto the private school account. Once the raw data were received, they were imported into SPSS, version 16, from Microsoft Excel spreadsheets to do the statistical analyses described in the data analysis section.

Quantitative Research Questions:

(1) Is there a relationship between the changes made in PBIS procedures (independent variable) and the numbers of problem behaviors (dependent variable) as measured by office discipline referrals over the 2007-2008 verses 2008-2009 school years for individual students with a history of office discipline referrals?

To determine if change occurred in individual student behavior when exposed to the new conditions put in place during the 2008-2009 school year, their office discipline referrals from the 2007-2008 (Key) year were compared to the 2008-2009 (PAWS) school year. Data for answering this question was taken from the SWIS data collection system. Students that were in attendance throughout both the 2007-2008 and the 2008-2009 school years, and had been given one or more office discipline referral in 
either or both years were selected. In 2007-2008 there were 48 students given referrals, and in 2008-2009 there were 56 students referred to the office. Due to the significant turnover rate at this school, the number available for comparison was only thirty-one students (see Table 2 in Appendix J).

(2) Has significant change occurred in the number of office discipline referrals by level $(0,1,2-5,6+)$ over the current school year as compared to previous years?

To evaluate the overall impact on the school population of the new strategies, the numbers of students falling into the categories of zero office discipline referrals (ODR's), one ODR, two to five ODR's and six or more ODR's were drawn from SWIS data that was collected by the school over the past seven years (see Tables 3 and 4 in Appendix F).

(3) How do the predictor variables of behavior points (monthly charts), token rewards (Treasure Tower coins), and teacher recognitions (coupons) relate to the number of office discipline referrals (criterion variable) for each student?

To determine the influence of the three criterion variables of behavior charting, PAW coupons, and coin rewards on student behavior, the totals for these variables on each student were tallied by each child on a monthly basis on pages kept in their PAW calendar, and the numbers were collected by the classroom teachers. These totals determined whether or not a coin was earned. The grand totals for the 2008-2009 school year were available from the teachers' classroom logs. 
Qualitative Research Question

(4) How do teachers and administrators, and students perceive the impact of the revised PBIS program on the school community?

To gain perspective on how teachers and administrators perceived the impact of the revised PBIS program on the school community, survey results were gathered from faculty, staff, and administrators of the elementary school using the PBS SelfAssessment Survey (see Appendix G). This survey asked for the evaluation of the PBIS program on four aspects: school wide, classroom, nonclassroom, and individual student systems. Respondents assessed the current status of a system component as being "In Place," "Partial", or "Not." Then the Improvement Priority was selected: "High", "Medium" and "Low." Twenty-eight people responded to the survey which was conducted online and anonymously in June 2009. The results were made available after June 30, 2009 to the school PBIS coach and members of the PBIS team.

Student perceptions were collected by means of a school -wide survey developed as part of the ongoing action research and conducted on October 6, 2008 (see Appendix H). The survey was constructed to provide information specifically about student perceptions of the universal program. The first portion used Likert scale judgments to investigate student response to some of the logistical components of the PAW program such as the coloring in of daily behavior onto the PAW calendar, and having the coupon boxes in the classrooms. The Likert scale also tapped the recognition theme with questions about getting coupons, the name draw, and the Treasure Tower buy. The sentence completions were about personal accountability specifically tied to the predictor variables of coupons, behavior charting/points, and 
earning of a Treasure Tower coin. Students were also given freedom to express whatever thoughts they had by completing an open response section of what they liked and did not like about the PAW program.

Once the surveys were completed, they were collected and stored by grade levels. The surveys were completed so that personal identifying information was only recorded on the backs of the surveys, and then this researcher generated a letter/numeric code for the purposes of this study. Again on May 17, 2009, students in one class each in grades two and three were given the same survey to complete.

\section{Data Analysis}

Question 1: In this study, individual student behavior was compared under the two conditions of PBIS procedures. Students who received ODR's in 2007-2008 under the Keys PBIS were compared to their own behavior during the 2008-2009 school year under the PAWS PBIS by looking at the absence or presence of referrals and the numbers that occurred. In the same way, students with no office discipline referrals during the 2007-2008 year were compared to the 2008-2009 year and the number of referrals they were given under the new conditions.

The Wilcoxon Signed Ranks test is used when there are two observations for one subject. This test was used to determine if there was a difference in student behavior from Keys year to PAWS year. The Wilcoxon Signed Ranks test is a nonparametric equivalent of the paired difference $t$-test. A check for normality of the PAW ODR frequencies, Key ODR frequencies, and the difference of PAW ODR-Key ODR using the Kolmogorov-Smirnov test for normality indicated that none of the three 
were normal. Because a $t$-test assumes normally skewed data, it could not be used on the data collected.

Question 2: Analysis of question 2 was accomplished by using the chisquare test for independence. The office referral data from the seven school years of PBIS participation yielded "observed frequencies", and the chi-square statistic generated "expected frequencies" which were compared to each year's actual frequencies to determine if there was a significant change in the numbers of children with no ODR, one ODR, two - five ODR, or six or more ODR. In this way, the children were classified into four categories for comparison.

The chi-square test for independence requires categories, and also two or more separate samples having the same proportions (Gravetter \& Wallnau, 2007). Although the data came from seven different school years, there have been no changes in the districting of this school, so children continued to come from the same area with the same general characteristics of economic diversity. A second concern was the consistency of application of PBIS for the years in question. PBIS was implemented with fidelity as evidenced by the school's participation in Project Target, a four year research study conducted by the Maryland State Department of Education, Sheppard Pratt Health System, and John Hopkins University. These entities verified fidelity for the school's first three years, and in two of the remaining years, the school was cited as an exemplar school, meaning it met criteria for fidelity with at least $80 \%$ compliance per the independent audit conducted by members of the State PBIS management team trained in the evaluation of PBIS schools (Barrett, 2008). The remaining year had no audit secondary to a schoolbased administrative decision not to participate in an audit for the 2007-2008 school 
year (S. Sisler, Assistant Principal, personal communication, November 7, 2008). Application made for the 2008-2009 school year resulted in the subject school being named a GOLD Recognition School, the highest level of recognition. The criteria for fidelity were met with $100 \%$ compliance.

Question 3: Analysis of the relative impact of each new component introduced in the PAWS system on the behavior of students was done using a coefficient of determination $\left(r^{2}\right)$. This allowed for a measurement of the degree and strength of relationships between the variables. (Gravetter \& Wallnau, 2007). A linear regression equation permitted estimation of the proportion of variance accounted for by the variables studied. For each student the predictor variables of behavior monitoring (calendar points), reward (coins), and recognition (coupons) were correlated to incidences of office discipline referrals (criterion variable).

Question 4 used results from the faculty/administration survey and the student survey. These results were evaluated for perceptions regarding the impact of the PAWS PBIS program on the school community.

The faculty/administration survey results arrived from the PBIS web service with percentages of responses already calculated and with highlighting of those questions where there were fewer than $80 \%$ positive responses (see Appendix $G$ ). For the purposes of answering the research question, the questions were taken through data reduction by sorting whether they related to either universal PBIS procedures, or disciplinary concerns for more intensive need students. They were then organized by whether there was a positive $(80 \%$ or better) or a negative (less than $80 \%$ ) faculty/administrative response. This allowed for the organized display 
and drawing of conclusions as proposed by Miles and Huberman's (1984) model of qualitative data analysis.

Student perceptions of the newly implemented PAWS program were tapped at the beginning of October, 2008, just after the first full month of following all the new procedures and after the first Treasure Tower buy. Surveys were completed by all grade levels with teacher administration and with my help in PreK and Kindergarten. In the upper grades, students were able to independently complete the questions using words or drawings. Data analysis occurred through a process of simplifying the student comments into general themes and a simple tally count was taken for each of the coded themes. The themes that developed were "recognition", "accountability" and "logistics". These perceptions were then organized by positive and negative comments, and complied by grade levels. In addition, the Likert scale items were summarized by frequency charting and calculation of the median and mode. As Likert data is ordinal in nature, it was not appropriate to determine a mean or standard deviation.

For the purposes of inter rater reliability, a classroom teacher from the school was trained in coding of open-ended questions, and in May, 2009, went through the surveys from three grades $\left(2^{\text {nd }}, 3^{\text {rd }}\right.$ and $\left.5^{\text {th }}\right)$ using coding schema previously derived by this researcher in October. A copy of only the front page of the surveys to be coded was given to the second rater so that there was no identifying information on the surveys analyzed.

In order to assess if there were changes in student perceptions from the beginning of the school year to its conclusion, a repeat sample, using the identical 
student survey was conducted in two classrooms on May 17,2009. As the faculty survey was completed at the end of the school year, it seemed reasonable to check on student perceptions after the "new" had perhaps worn off the PAWS program.

In addition, by collecting repeated surveys from these two classrooms, it allowed for the specific analysis of students for whom the new program may have had particular influences. Four students were selected based on the numbers of office discipline referrals received, or not received across both the Keys program year and the PAWS in answering research question one.

These four students generated eight surveys. Both the trained co-coder and I looked at the surveys for variations in responses both across student by time of year, and by student based on personal behavior as evidenced by the occurrences of, or lack of, office discipline referrals (see Table 5).

Table 5 Selection matrix for student surveys

\begin{tabular}{|c|c|c|}
\hline $\begin{array}{c}\text { Total Office Discipline Referrals } \\
\text { (ODR) per academic year }\end{array}$ & $\begin{array}{c}\text { High ODR (6+) in 2007 } \\
-2008\end{array}$ & $\begin{array}{c}\text { Zero ODR in } \\
2007-2008\end{array}$ \\
\hline $\begin{array}{c}\text { High ODR (6+) in } \\
2008-2009\end{array}$ & Student 1 & Student 2 \\
\hline Zero ODR & & \\
in 2008-2009 & Student 3 & Student 4 \\
\hline
\end{tabular}




\section{Summary}

The population for this study was drawn from one Pre-K through fifth grade elementary school. Additionally, the faculty and staff were tapped for qualitative survey responses. Research question 1 included those students who attended the study elementary school for the entirety of both 2007-2008 and 2008-2009 school years. The sample size was thirty-one students. Research question 2 looked at archived data for seven academic school years beginning in 2002, running through 2009, and encompassing the entire school population for each year. For question 2 there were a total of 2112 students across those seven years of data. Question 3 utilized data obtained for all students in attendance for the entire 2008-2009 school year. The sample was 260 students. For question 4 , the faculty survey had twentyeight responses, while the October and May student survey had a sample size of 287.

Data was collected using extant information generated over the course of the 2008-2009 school year along with archived data from previous school years beginning in 2002. The numerical information came in the form of office discipline referrals as recorded by school administration and student tallies of earned points, coupons and coins. Qualitative data was derived from surveys developed as part of the school action research plan and collected in October 2008 and May 2009. Analysis of this data was accomplished using SPSS, version 16, to conduct a nonparametric test, the Wilcoxon Ranked Sign test, and two parametric tests, the Chi-Square test of independence, and the coefficient of determination along with 
linear regression equations. Qualitative data was coded by positive and negative responses and transformed into numerical counts. 


\section{CHAPTER FOUR}

\section{RESULTS}

The purpose of this chapter is to present the findings of the data analysis performed on the quantitative research questions 1,2 , and 3 , and to provide data displays for the qualitative research question 4. Results of the data analysis are presented to answer the research questions used to guide the research study. The questions were as follows:

\section{Quantitative Research Question 1}

Is there a relationship between the changes made in PBIS procedures (independent variable) and the numbers of problem behaviors (dependent variable) as measured by office discipline referrals over the 2007-2008 Key verses 2008-2009 PAWS school years for individual students with a history of office discipline referrals?

For this question, the $\mathrm{H}_{0}$ was: there is no difference from Key to PAWS school years in the numbers of office discipline referrals for individual students.

As discussed in Chapter three, the Wilcoxon Signed Ranks test was used rather than a paired sample $t$-Test because of the lack of normality in the data. The Kolmogorov-Smirnov Test for normality when applied to the Key year frequency distribution, and the PAW year data frequency distributions were found to be not normal with a $p<.001$. The frequency distribution histograms below illustrate the positive skew on both sets of data. 


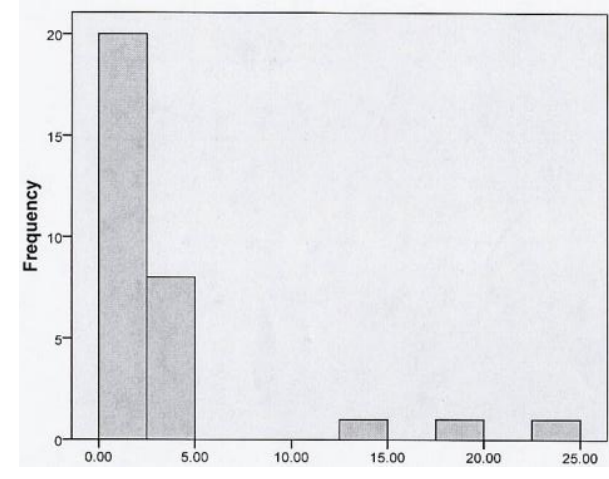

Figure 3: PAWS year ODR frequency

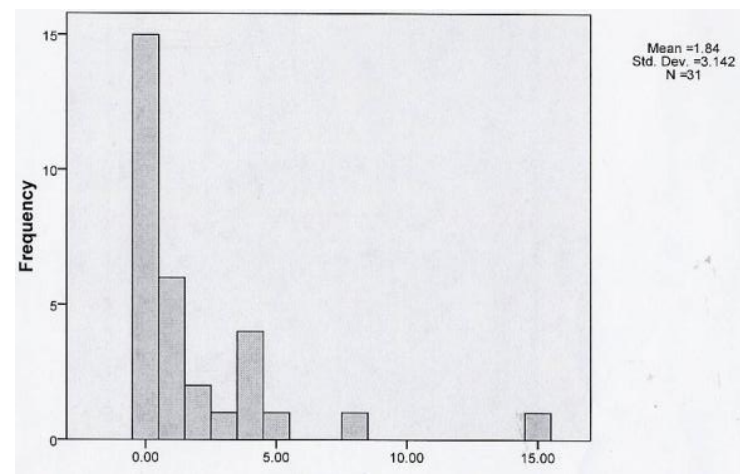

Figure 4: Key year ODR frequency

Note: $x$ axis $=$ number of referrals, $y$ axis $=$ number of students

Calculation of the Wilcoxon signed ranks test involved comparing the number of office discipline referrals generated by individual students in the Key program year (2007-2008) verses the PAW program year (2008-2009). These numbers were ranked by whether they were higher from year Key to year PAW, or lower, for each student (see Table 2). The statistical analysis discarded tied scores, and so four (4) were not included as they had the same number of office referrals in both years. The results for the remaining twenty-seven (27) students showed that there was no significant decrease in the number of office discipline referrals for individual students with a history of referrals during the conditions of the new PAWS program. Of the students observed, there were more children, (twenty), who had more referrals ( $M=$ $13.42, \mathrm{SS}=268.50)$ under PAWS and seven $(7)$ who had fewer referrals $(M=15.64$, $S S=109.5)$ during PAWS. The Wilcoxon Signed Ranks test did not reveal a significant difference in student responsiveness during the PAW year $(M=3.42, S D=5.37)$ versus the Key year $(M=1.84, S D=3.14), N=27, z=-1.932, p=.053$. Therefore, the $H_{0}$ was not rejected. 


\section{Quantitative Research Question 2}

Has significant change occurred in the total number of office discipline referrals by level $(0,1,2-5,6+)$ over the $2008-2009$ school year as compared to each of the six previous years?

For this question, the $\mathrm{H}_{0}$ was: the distribution of office discipline referrals had the same proportions for all the years of PBIS implementation.

The percentages of students receiving office discipline referrals in each classification level of interest showed a decline among all grades and across all the years of PBIS implementation in this school, particularly comparatively between the years $2002-2003$ and $2007-2008$ (see Table 6). Using a chi-square test of independence, the relationship between the number of office discipline referrals (ODR) and all academic years was significant, $X^{2}(\mathrm{df}=18, \mathrm{~N}=2112)=45.579, p<.005$ (see Table 7). Effect size was calculated using Cramér's $V=.085$, and indicated a small to medium effect. (Gravetter \& Wallnau, 2007, p. 603). Therefore the $\mathrm{H}_{0}$ was rejected. 
Table 6 Chi-Square Test Note:

a. observed frequency of office discipline referrals $(O D R) b$. expected frequency of ODR $c$. Chi - Sq for cell. Chi-Sq total $=45.579, p<0.005$

\begin{tabular}{|c|c|c|c|c|c|c|c|c|}
\hline School Years & 2002-2003 & 2003-2004 & 2004-2005 & 2005-2006 & 2006-2007 & $\begin{array}{l}2007- \\
2008\end{array}$ & $\begin{array}{l}2008- \\
2009\end{array}$ & Total \\
\hline 0 ODR & $\begin{array}{l}\text { a. } 208 \\
\text { b. } 244.22 \\
\text { c. } 5.372\end{array}$ & $\begin{array}{l}\text { a. } 217 \\
\text { b. } 225.02 \\
\text { c. } 0.286\end{array}$ & $\begin{array}{l}\text { a. } 245 \\
\text { b. } 244.99 \\
\text { c. } 0.000\end{array}$ & $\begin{array}{l}\text { a. } 231 \\
\text { b. } 221.95 \\
\text { c. } 0.369\end{array}$ & $\begin{array}{l}\text { a. } 203 \\
\text { b. } 208.13 \\
\text { c. } 0.126\end{array}$ & $\begin{array}{l}\text { a. } 272 \\
\text { b. } 245.76 \\
\text { c. } 2.802\end{array}$ & $\begin{array}{l}\text { a. } 246 \\
\text { b. } 231.9 \\
\text { c. } 0.853\end{array}$ & $\begin{array}{c}N= \\
1622\end{array}$ \\
\hline 1 ODR & $\begin{array}{l}\text { a. } 47 \\
\text { b. } 29.36 \\
\text { c. } 10.597\end{array}$ & $\begin{array}{l}\text { a. } 31 \\
\text { b. } 27.05 \\
\text { c. } 0.576\end{array}$ & $\begin{array}{l}\text { a. } 27 \\
\text { b. } 29.45 \\
\text { c. } 0.204\end{array}$ & $\begin{array}{l}\text { a. } 22 \\
\text { b. } 26.68 \\
\text { c. } 0.822\end{array}$ & $\begin{array}{l}\text { a. } 27 \\
\text { b. } 25.02 \\
\text { c. } 0.156\end{array}$ & $\begin{array}{l}\text { a. } 19 \\
\text { b. } 29.55 \\
\text { c. } 3.764\end{array}$ & $\begin{array}{l}\text { a. } 22 \\
\text { b. } 27.88 \\
\text { c. } 1.241\end{array}$ & $\mathrm{~N}=195$ \\
\hline 2 - 5 ODR & $\begin{array}{l}\text { a. } 39 \\
\text { b. } 28.91 \\
\text { c. } 3.522\end{array}$ & $\begin{array}{l}\text { a. } 31 \\
\text { b. } 26.64 \\
\text { c. } 0.715\end{array}$ & $\begin{array}{l}\text { a. } 28 \\
\text { b. } 29.00 \\
\text { c. } 0.034\end{array}$ & $\begin{array}{l}\text { a. } 26 \\
\text { b. } 26.27 \\
\text { c. } 0.003\end{array}$ & $\begin{array}{l}\text { a. } 27 \\
\text { b. } 24.64 \\
\text { c. } 0.227\end{array}$ & $\begin{array}{l}\text { a. } 18 \\
\text { b. } 29.09 \\
\text { c. } 4.228\end{array}$ & $\begin{array}{l}\text { a. } 23 \\
\text { b. } 27.45 \\
\text { c. } 0.723\end{array}$ & $N=192$ \\
\hline 6 or more & $\begin{array}{l}\text { a. } 24 \\
\text { b. } 15.51 \\
\text { c. } 4.649\end{array}$ & $\begin{array}{l}\text { a. } 14 \\
\text { b. } 14.29 \\
\text { c. } 0.006\end{array}$ & $\begin{array}{l}\text { a. } 19 \\
\text { b. } 15.56 \\
\text { c. } 0.762\end{array}$ & $\begin{array}{l}\text { a. } 10 \\
\text { b. } 14.09 \\
\text { c. } 0.003\end{array}$ & $\begin{array}{l}\text { a. } 14 \\
\text { b. } 13.22 \\
\text { c. } 0.046\end{array}$ & $\begin{array}{l}\text { a. } 11 \\
\text { b. } 15.61 \\
\text { c. } 1.359\end{array}$ & $\begin{array}{l}\text { a. } 11 \\
\text { b. } 14.73 \\
\text { c. } 0.944\end{array}$ & $N=103$ \\
\hline Total & $N=318$ & $N=293$ & $N=319$ & $N=289$ & $N=271$ & $N=320$ & $N=302$ & $\begin{array}{c}\mathrm{N}= \\
2112\end{array}$ \\
\hline
\end{tabular}

Specific comparison between the years under investigation in this study, 2007 2008 and $2008-2009$, did not indicate a significant relationship between the numbers of office discipline referrals by category (e.g. I ODR, $2-5$ ODR, etc.) or by totals, $X^{2}$ (3, $\mathrm{N}=622)=1.615, \mathrm{p}=0.656$. In this case the $\mathrm{H}_{0}$ was that the treatment year was the same as the previous year in proportions of ODR across categories, and the $\mathrm{H}_{0}$ was not rejected.

\section{Quantitative Research Question 3}

How do the predictor variables (a., b., c.) relate to the number of office discipline referrals (criterion variable) for each student?

a. behavior points (monthly charts)

b. token rewards (Treasure Tower coins) 


\section{c. teacher recognitions (coupons)}

The anticipated correlation was expected to be a negative one where increased positives yield decreased negatives (or Office Discipline Referrals as the criterion variable), based on research on the effects of rewards on behavior (Ayllon \& Azrin, 1968; Sharpley, 1988; Horner, Todd, Lewis-Parker, Ivin, Sugai, Boland, 2004; Fabiano, et al, 2008). This anticipated result was confirmed by the coefficient of determination, $r^{2}$ $=.137, \mathrm{~F}(3, \mathrm{~N}=260)=13.547, p<.001$. The regression equation showed that only $13.7 \%$ of the variance in office discipline referrals was explainable by the predictor variables of behavior points (monthly charts), token rewards (coins), and teacher recognitions (coupons).

To reference criteria suggested by Cohen, an $r^{2}=0.09$ represents a medium effect, and $r^{2}=0.25$ represents a large effect size (Gravetter \& Wallnau, 2007, p. 288), therefore, this effect size, $r^{2}=.137$, fell within the medium range.

As office discipline referrals (ODR) was the dependent variable, a regression analysis was performed between the ODR and the predictor variables of coupons, coins, and behavior points. In terms of individual relationships, significant correlations existed between ODR and points $(t=-0.336, p<.001)$; and ODR and coins $(t=-0.313$, $p<.001)$. There was a non-significant relationship between ODR and coupons $(t=-0.103, p=.098)$ (Morgan, Reichert, \& Harrison, 2002) (see Table 7). 
Table 7 Correlations of Independent and Dependent Variables

\begin{tabular}{|c|c|c|c|c|c|}
\hline $\begin{array}{l}\text { Descriptive } \\
\text { Stats }\end{array}$ & & Points & Coins & Coupons & ODR \\
\hline $\begin{array}{l}M=155.74 \\
S D=29.50 \\
S u m=40,647 \\
N=260\end{array}$ & $\begin{array}{l}\text { Points } \\
\text { Pearson } \\
\text { Sig. }\end{array}$ & 1.000 & & & \\
\hline $\begin{array}{l}M=8.20 \\
S D=1.47 \\
\text { Sum }=2141 \\
N=260\end{array}$ & $\begin{array}{l}\text { Coins } \\
\text { Pearson } \\
\text { Sig. }\end{array}$ & $\begin{array}{l}.752 \\
.000\end{array}$ & 1.000 & & \\
\hline $\begin{array}{l}M=63.62 \\
S D=38.18 \\
S u m=16,604 \\
N=260\end{array}$ & $\begin{array}{l}\text { Coupons } \\
\text { Pearson } \\
\text { Sig. }\end{array}$ & $\begin{array}{l}.627 \\
.000\end{array}$ & $\begin{array}{l}.393 \\
.000\end{array}$ & 1.00 & \\
\hline $\begin{array}{l}M=4.69 \\
S E=6.34 \\
\text { Sum }=262 \\
N=56\end{array}$ & $\begin{array}{l}\text { ODR } \\
\text { Pearson } \\
\text { Sig. }\end{array}$ & $\begin{array}{l}-.336 \\
.000\end{array}$ & $\begin{array}{l}-.313 \\
.000\end{array}$ & $\begin{array}{l}-.103 \\
.098\end{array}$ & 1.000 \\
\hline
\end{tabular}

Qualitative Research Question 4

How do teachers and administrators, and students perceive the impact of the revised PBIS program on themselves and the school community?

\section{Teacher and Administrator Survey}

The EBS Self Assessment survey (see Appendix G) was developed by Sugai, Horner, and Todd (2000) and is used by school staff across the country for initial and annual assessment of effective behavior support systems in their school. The intent of the survey is to facilitate school planning and highlight perceived areas of needed improvement. For this study, the questions were sorted by whether they addressed the universal or school-wide applications of PBIS, or if they were directed at more intensive, individualized student needs. Using this focus, the forty-six questions were divided into thirty-two relating to the universal aspects of PBIS, and fourteen relating to more 
intensive, individualized aspects. If the question was given $80 \%$ or better rating of current status "In Place," the question was regarded as being positively viewed or as a strength. Questions with less than $80 \%$ staff agreement of being "In Place," were regarded as being negatively viewed, or as a weakness. The breakdown of responses below reflects the overall strength of the universal system under PAWS, and the perceived needs for improvement in the individualized responses within PBIS.

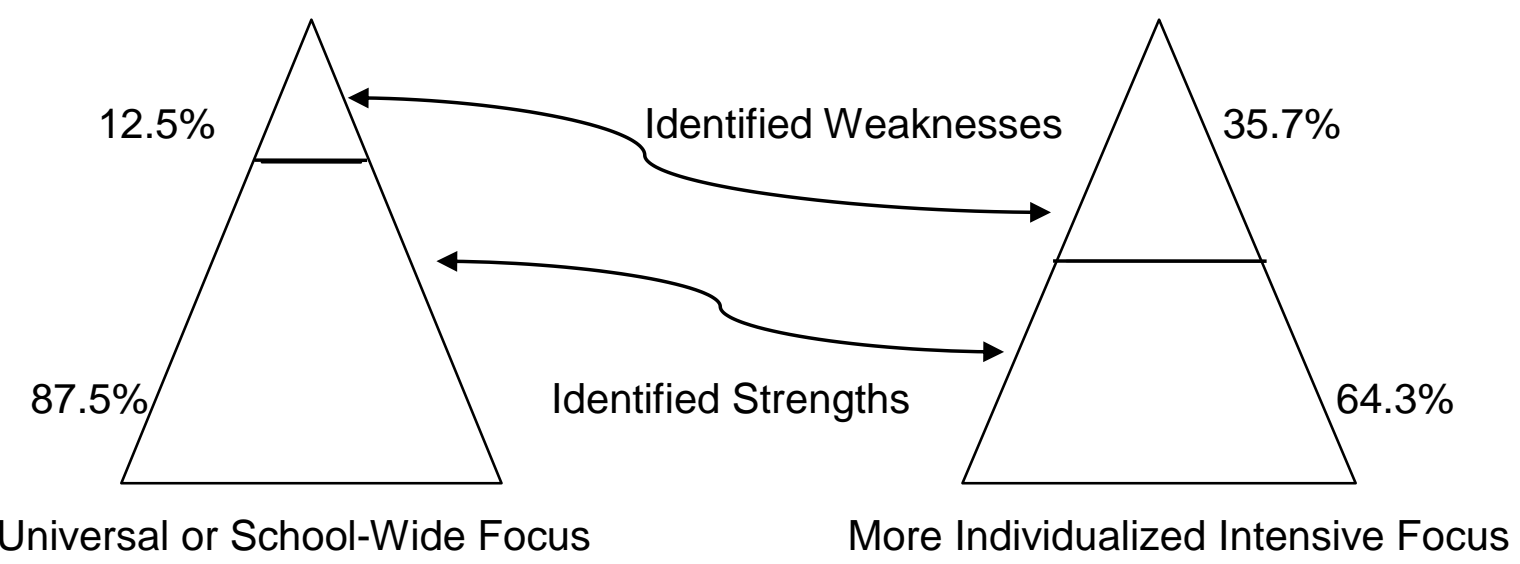

Figure 5: Respondents Perceptions of PAWS strengths and weaknesses

Perceived Universal System strengths included:

$\nabla$ A small number (e.g. $3-5$ ) of positively and clearly stated student expectations or rules are defined. $(100 \%$ of staff agreed that this was "In Place").

$\nabla$ Expected student behaviors are rewarded regularly. (93\% of staff agreed that this was "In Place"). 
$\nabla$ Expected student behaviors \& routines in classrooms are taught directly. (100\% of staff agreed that this was "In Place").

Perceived Universal System Weaknesses:

$\nabla$ Problem behaviors (failure to meet expected student behaviors) are defined clearly. (only $79 \%$ of staff agreed that this was "In Place").

$\nabla$ Consequences for problem behaviors are defined clearly. (only $64 \%$ of staff agreed that this was "In Place").

While the universal system was regarded as being a very positive effect in the school under the newly implemented PAWS protocol, there were apparent areas of weakness, particularly in regard to questions that more directly reflected PBIS procedures for specific individual problems. On those questions directed toward staff opinion about how individual student behaviors were managed, approximately two thirds of the responses were positive, however, about one third were negative. This was in contrast to the nearly $90 \%$ positive to $10 \%$ negative findings about the universal system features.

Among the $64.3 \%$ of noted strengths in the more individualized aspects of the school's PBIS procedures were responses to the following questions:

$\nabla$ A team exists for behavior support planning \& problem solving $(93 \%$ of staff saw this as being "In Place"). 
$\nabla$ Classroom-based options exist to allow classroom instruction to continue when problem behavior occurs (93\% believed this to be "In Place").

$\nabla$ Behavior is monitored \& feedback provided regularly to the behavior support team \& relevant staff (89\% agreed that this was "In Place").

Perceived Individual System Weaknesses:

$\nabla$ Distinctions between office $v$. classroom managed problem behaviors are clear (only $68 \%$ of staff believed this to be "In Place").

$\nabla$ Problem behaviors receive consistent consequences (only $68 \%$ of staff agreed that this was "In Place").

$\nabla$ School includes formal opportunities for families to receive training on behavioral support/positive parenting strategies (only $61 \%$ of staff believed this to be "In Place").

\section{Student Surveys}

A school wide survey was administered at the beginning of October 2008. The purpose was to assess student reaction to the universal aspects of the PAWS program and obtain feedback about the various components put in place. The survey consisted of three open ended questions, five Likert scale questions, and two free responses about what was liked and not liked about the new PAWS program. The structure of the survey targeted the logistics of the program through the Likert scale questions, student accountability via the open ended questions, and general thoughts with the free 
responses. On this initial survey, a total of 287 surveys were completed (see Appendix $H)$.

As this was completed by grades PreK through fifth, there were modifications for the primary grades. For the primary grades, on the Likert scale questions, a series of "smiley faces" icons were displayed showing variations of expression from open smile, smile, flat mouth, frown, and big frown that represented the scale of $1-5$ or "Great," "Good," "Doesn't Matter," "Not Good" and "Bad". Students were instructed to color in the face that showed best how they felt about each question. Also, students were given the option to draw responses rather than write, or to use a teacher or assistant as writer, and invented spelling was accepted.

The responses from the surveys were summarized by recording each response by question, and using a simple tally count to quantify the number of times a response could be classified as positive or negative. The students' statements were also coded by the themes of "recognition", "rewards", and "logistics." In May, a trained coder independently coded student surveys from three grade levels (2, 3, and 5). An index of reliability (Perreault \& Leigh, 1989) was computed to assess the reliability of the coding of positive and negative responses done by the each coder comparative to the other. This analysis yielded an Index of Reliability $\left(I_{r}\right)$ of .947 for the grade two surveys, an $I_{r}$ of .923 for third grade, and an $I_{r}$ of 1.0 for fifth grade. Given the high level of reliability, the remaining surveys from October which were coded only by this researcher were judged to be reliably coded as well. The repeat surveys done in May in grade two and three were also coded independently by the trained teacher and me. Again, the Index of 
Reliability was high for reliability in discerning positive and negative responses with $I_{r}=$ 1.0.

For each survey collection and within each category of positive and negative comments, the themes of "recognition," "accountability," and "logistics" were coded and tallied to provide a sense of the level of student acceptance of the changes put into place for the 2008-2009 school year. Again, inter rater reliability was acceptable with an $I_{r}$ for second grade of .763 , and for third grade of .826 .

The open ended survey responses were first coded by positive and negative reactions, and then further broken down into the themes of "recognition," "accountability," and "logistics." Because of the limited time that the kindergarten and Pre-K students had in experiencing the PBIS framework, the responses from these grades were not incorporated into this study's analysis. The total number of student surveys coded for this study, October 2008 and May 2009, combined was 240. The following descriptive matrix, as suggested by Miles and Huberman (1984), displays examples from grades one through five that were taken from the "What I like about PAWS..." / "What I don't like about PAWS..." free response section of the survey. Student spelling has been preserved. 


\begin{tabular}{|c|c|c|c|}
\hline & Recognition & Accountability & Logistics \\
\hline $\begin{array}{l}\text { POSITIVE COMMENTS } \\
\mathrm{N}=351(79.59 \%)\end{array}$ & $\begin{array}{l}\text { "because evreyone gets } \\
\text { an award" ( } 3^{\text {rd }} \text { grader) } \\
\text { "they call my name out } \\
\text { on the announsments" } \\
\left(4^{\text {th }} \text { grader }\right)\end{array}$ & $\begin{array}{l}\text { I get paws when I be } \\
\text { there, be safe, be } \\
\text { respectful, be } \\
\text { responsible" }\left(2^{\text {nd }} \text { grader }\right) \\
\text { "because you are very } \\
\text { good and you earn } \\
\left.\text { things ( } 11^{\text {st }} \text { grader }\right)\end{array}$ & $\begin{array}{l}\text { "I get to put them in the } \\
\text { box in my room I don't } \\
\text { have too run } \\
\text { downstairs" ( } 5^{\text {th }} \text { grader) } \\
\text { "When I color in the } \\
\text { Paws" ( } 1^{\text {st }} \text { grader) }\end{array}$ \\
\hline $\begin{array}{l}\text { NEGATIVE } \\
\text { COMMENTS } \\
\mathrm{N}=90(20.41 \%)\end{array}$ & $\begin{array}{l}\text { "I don't like not get } \\
\text { piked out of the paws } \\
\text { box" ( } 2^{\text {nd }} \text { grader) } \\
\text { "When I don't get my } \\
\text { name drawed out. }\left(1^{\text {st }}\right. \\
\text { grader) }\end{array}$ & $\begin{array}{l}\text { "because you have to be } \\
\text { really good"( } 3^{\text {rd }} \text { grader) } \\
\text { "when I don't get one } \\
\text { when I wasn't talking } \\
\text { and being quiet." (5 } 5^{\text {th }} \\
\text { grader) }\end{array}$ & $\begin{array}{l}\text { "you have to color in } \\
\text { the calendar" }\left(4^{\text {th }}\right. \\
\text { grader) } \\
\text { "I have to write my } \\
\text { name on the back" }\left(2^{\text {nd }}\right. \\
\text { grader })\end{array}$ \\
\hline
\end{tabular}

Figure 6: Free response matrix

The Likert scale questions were designed to address the student acceptance of the new components of PAWS, specifically the name draw in the rooms, the coloring in of the PAW calendar with their daily behavior color, and the Treasure Tower buy.

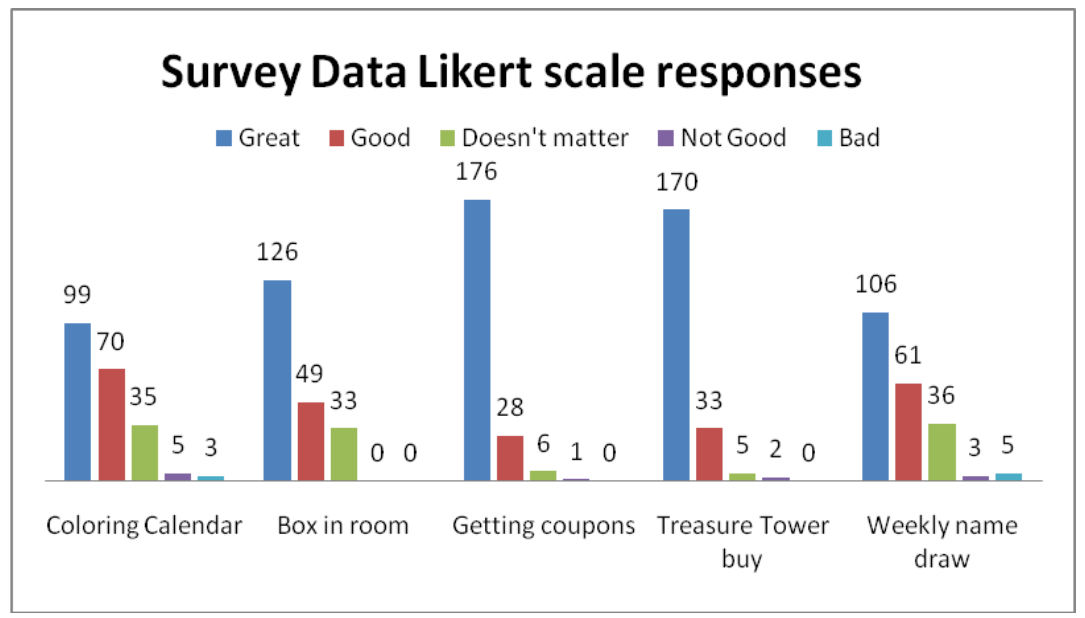

Figure 7: October 2008 results 
As Figure 7 shows, students overwhelmingly viewed the PAW components positively, and had a particularly favorable opinion of the Treasure Tower buying reward, and the receipt of coupons.

Similar results occurred, although on a smaller scale with the surveys completed in May by two classrooms. The data showed a positive skew, and the most positive responses remained those for receiving coupons and buying from the Treasure Tower, which required earning a coin.

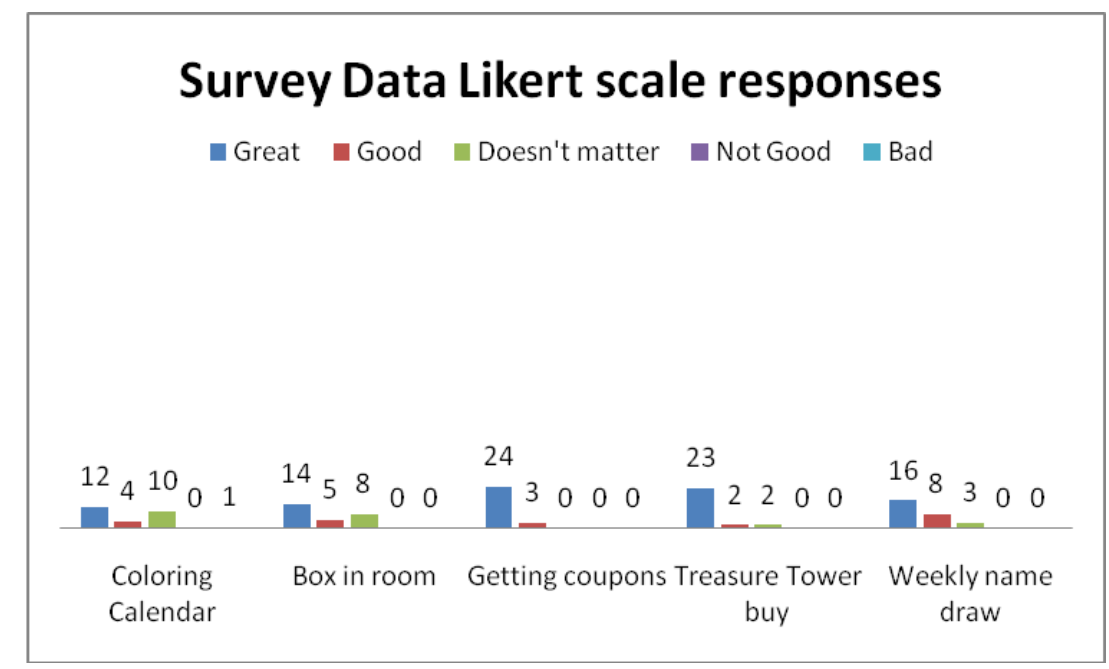

Figure 8: May 2009 results

General findings from these student responses confirmed that students had an overwhelmingly positive response to the PAWS program changes. From their perspective, the Treasure Tower was successful - not one complaint about the buying process from the students. Also, they saw the lunch table as a huge reward and its weekly frequency made it more immediate to the students. The idea between the points, the calendar, and the Tower seemed clearly understood by the majority of participants. Comparison between the October survey and the May survey had few 
differences. The Likert scale responses were similar, and the open ended questions had equivalent proportions of positive and negative comments. By the end of the year, the recognition aspects of the PAW program still generated the majority of positive observations in the free response section, but with many fewer about the logistics, compared to October.

To further explore the qualitative question, one additional comparison was made using specific sampling of surveys drawn from the pool of surveys. These were selected based on the office discipline referrals (ODR) acquired by four students over the two years under study (see Table 5).

\section{Table 5 Selection matrix for student surveys}

\begin{tabular}{|c|c|c|}
\hline $\begin{array}{c}\text { Total Office Discipline Referrals } \\
\text { (ODR) per academic year }\end{array}$ & $\begin{array}{c}\text { High ODR (6+) in } \\
\text { Key 2007-2008 }\end{array}$ & $\begin{array}{c}\text { Zero ODR in } \\
\text { Key 2007 - 2008 }\end{array}$ \\
\hline $\begin{array}{c}\text { High ODR (6+) in } \\
\text { PAWS 2008 - 2009 }\end{array}$ & Student 1 & Student 2 \\
\hline $\begin{array}{c}\text { Zero ODR in } \\
\text { PAWS 2008 }-2009\end{array}$ & Student 3 & Student 4 \\
\hline
\end{tabular}

These student surveys were again coded by both the trained teacher and this researcher. Of particular interest was the search for any change in perception evidenced over the course of the 2008-2009 school year for these students who had such a varied experience relative to office discipline referrals.

The analysis of these four individual surveys showed a pattern of responses that mirrored the pattern of ODR that occurred during the PAWS year, as illustrated in the chart below, with student 2 being the one exception. 


\section{Table 8 Individual Student Survey Responses}

\begin{tabular}{|c|c|c|}
\hline & $\begin{array}{l}\text { High ODR (6+) in } \\
\text { Key } 2007-2008\end{array}$ & $\begin{array}{c}\text { Zero ODR in } \\
\text { Key } 2007-2008\end{array}$ \\
\hline $\begin{array}{l}\text { High ODR }(6+) \text { in } \\
\text { PAWS } 2008-2009\end{array}$ & Student 1 & Stud \\
\hline $\begin{array}{c}\text { Zero ODR in } \\
\text { PAWS } 2008-2009\end{array}$ & & \\
\hline
\end{tabular}

Student 1 , a fifth grader, had a history of high numbers of referrals in the Key year. In the beginning of the new program, the responses were very positive, with "1" answers for all five Likert scale questions; indications of desire for the respect and recognition gained from the positive rewards associated with the PAWS approach. By May, as the number of ODR reflected a decline in behavior, $\rightarrow$ the responses also $\rightarrow$ became more negative. In May, the calendar points and coupons were still "1", but the name draw and Treasure Tower buy were both "4," meaning "not good." Those two components were dependent on having enough coupons and behavior points to earn the coin to buy with, and to increase the odds of being selected to eat at the PAW table. With a high number of ODR, it was unlikely that this student was able to accrue the necessary points, and consequently, it seemed feasible that they were seen as unobtainable.

Student 2, a third grader, had no referrals during the previous year, but accrued significant referrals during PAWS year. There was little enthusiasm for PAWS in October, with everything but the coupons and Treasure Tower buy given a "3" meaning 
"doesn't matter" on the Likert scale. The fill-in-the-blank answers were generic in nature, and only on the open-ended questions were there specific examples, What I like about PAWS, "you sit at the table with other people," and, What I don't like about $\underline{P A W S}$, "nothing." Even though the office discipline referrals increased, meaning behavior deteriorated over the year, the survey responses became more positive in

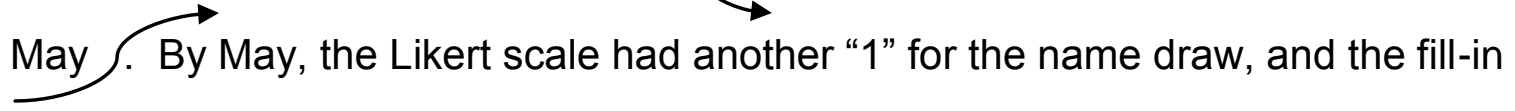
sentences became more specific. The answers to the What I like/don't like open responses were exactly the same.

Student 3, a second grader, and student 4, a third grader, both followed a pattern that reflected their behavior. Student 3 went from many referrals the previous year, to zero referrals indicating much improved behavior and the survey responses from October to May mirrored the improved opinion about PAWS . The Likert scale increased from a mode of "2" to a mode of "1." What was liked in October was "going to the Treasure Tower," and in May, it was "everything." Fill-in answers became much more specific and positive. Student 4 had no referrals under either PBIS program, and the survey responses were consistently positive $\longrightarrow$ in both October and May.

\section{Summary}

The data collected during the course of this correlational study was comprised of both quantitative and qualitative information. The first three research questions were analyzed statistically using the Wilcoxon Signed Ranks test, a Chi-square, and a coefficient of determination. Data that looked at student response to the PAWS program on an individual level found there was not a statistically significant difference 
from the previous year and the target year. On the macro level, there was a significant finding in comparing the impact of PBIS across a span of seven years of implementation, but there was not a significant difference when comparing the two years under examination. The final quantitative question, while finding a significant relationship between the coins, and behavior points and office discipline referrals, was only able to account for just over $13 \%$ of the variance in office discipline referrals.

The raw data from the qualitative surveys were transformed into data displays with coding used to quantify the results in order to facilitate understanding of the information. School-wide response to the PAWS program was very positive from both student and faculty perspectives. The responses from students remained positive over the course of the school year. In examining specific students according to behavioral characteristics as measured by office discipline referrals, the patterns of survey responses mirrored the pattern of office referrals for three of the four students.

The following chapter interprets the statistical and qualitative data to arrive at conclusions and attempts to understand this experience as evidenced by the information compiled in this research study. 


\title{
Chapter Five
}

\section{FINDINGS, DISCUSSION, CONCLUSIONS}

\author{
Introduction
}

The aim of this mixed method, embedded correlational study was to make explicit the relationships between changed procedures in one school's PBIS universal program and student behavior as measured by office discipline referrals. A secondary aim was to use student and faculty responses on surveys to interpret participants' reactions to the universal PBIS program changes introduced during the 2008-2009 school year.

\section{Findings}

The major questions that were investigated using quantitative analysis addressed the impact of PAWS PBIS program on individual students, on total school discipline, and the influence of selected PAWS components on student behavior. These data analysis yielded three major findings. One, there was no statistically significant effect of the PAWS program on the behavior of individual students when comparing their office discipline referrals from the Key year (2007-2008) and the PAWS year (2008-2009). Two, when looking at the changes over time for entire school populations in this elementary school, there was a statistically significant effect across the seven years of PBIS implementation, particularly when comparing the first year to the Keys year, but there was no statistical significance in whole school student behavior as measured by office discipline referrals between Key year and PAWS year. Three, when looking for the impact of the various changes made in the PBIS program with regard to rewards 
and self-monitoring, the results indicated statistically significant influences on individual student office discipline referral (ODR) rates, but these only accounted for $13.7 \%$ of the variance in the ODR generated. The individual relationships between ODR and coins and ODR and behavior points were statistically significant. No significant correlation was found between coupons received and office discipline referrals given to individual students.

Secondary findings were drawn from the qualitative data. These data analysis yielded one major finding. Survey responses that investigated the student and faculty reactions to the new program were overwhelmingly positive. Coding of positive and negative results and analysis of themes showed a strong response by the students that was maintained across the school year. The students had a great appreciation for the recognitions, and easily associated the target positive behaviors with the coupons, coins, and behavior points they were able to earn each day. Faculty had highly positive perspectives of the universal PAWS program as well, with areas of concern mainly focused on issues related to more individualized intervention needs. Even the children who had considerable behavioral challenges over the PAWS school year, had generally positive feelings about the universal program and were able to express understanding of the concepts of the school-wide target behaviors of "Be There," "Be Safe," "Be Respectful," and "Be Responsible."

\section{Conclusions}

The statistical results of this research were not what were hoped for when the study began. The lack of impact on overall student behavior both individually and across the school was unexpected because of the theory (Deci, Ryan, \& Koestner, 
1999) and research (Greitemeyer, \& Kazemi, 2008; Sugai \& Horner, 2002; Tymchuk, 1971) that appeared to predict an increase in positive behaviors would accompany the increase in positive rewards.

Conclusion 1: To cause large effects requires smaller, focused efforts.

For other schools engaged in the PBIS process, these results suggest that once an effective PBIS program is functioning reliably, to further impact the number of office discipline referrals, specific interventions for those students with two or more office discipline referrals needs to become an integral part of the school's PBIS approach. In this case, simply increasing the rewards and recognitions of the universal program was not sufficient.

Assessing the relative value of the program's reinforcement on behavior demonstrated that while points for daily behavior, and "Treasure Tower" coins had some correlation to whether or not a child misbehaved, there were many other, unknown factors that also must have played a major part in what motivated a child to behave or not. With only $13.7 \%$ of the variance in office discipline referrals being explained by the Universal components of counting of daily behavior points, and distribution of coins, it is clear that more targeted approaches are needed for those children unable to function within the school social system.

On a macro system level, the new PAWS program created renewed interest and excitement in the school. The student surveys expressed much happiness with the changes made in the number of students who earned rewards and in the increased opportunities for recognition. Unfortunately, on a micro system level, the universal system was unsuccessful in swaying even those children who could compare the 
greatly increased "treasure" with their own previous experiences, and yet whose behavior warranted office referrals anyway (see Table 2, Appendix J).

If PBIS schools wish to move beyond the behavior triangle of $80 \%$ of students with $0-1$ referral, $15 \%$ with $2-5$ referrals, and $5 \%$ with 6 or more, then the individual needs to become more of a focus. The most visible children, those whose behavior is most aggressive and disruptive have in place procedures such as Functional Behavior Assessments and Behavior Intervention Plans. It is the secondary level group that requires interventions in a more personalized manner than is provided by the universal system. Teacher responses on the Self-Assessment survey support this conclusion as well, with a third of the comments related to individual behavior management decisions felt not to be in place.

Conclusion 2: To sustain a positive environment requires purposeful change.

While the primary quantitative findings did not provide statistical validation of the modifications made in the universal PBIS strategies, the qualitative findings did support that the changes made a very positive improvement in student attitude toward the universal PBIS program. In August, the original action survey about the Key program had yielded only $57.3 \%$ positive comments and $43.7 \%$ negative comments. The student body overwhelmingly responded with enthusiasm and positive comments regarding all aspects of the PAWS innovations. The increase in recognitions and rewards were highly valued by students and positive reactions actually were higher by May than in October. In October, $77.8 \%$ was the average of positive responses across grades, while in May, $89.5 \%$ were positive from the two grades surveyed. Additionally, 
a large percentage $(87.5 \%)$ of the faculty and staff survey responses indicated that they believed that the universal program was implemented positively.

Based on the school PBIS team's established criteria of increasing the number of students recognized for positive behaviors, refreshing and inspiring renewed interest in PBIS, facilitating decreases in office discipline referrals and reducing the increase in referrals seen each year in the spring months, the 2008-2009 school year met those goals. While the office referrals did not significantly decrease, neither did they increase, even given the presence of two students who ultimately had to be placed in another school's behavior classroom setting

The work of the PBIS team in the summer before PAWS began, and the changes then made to aspects of the program based on student comments, created a system that continued the positive accomplishments of the past. "When decisions regarding the relevance, desirability, appropriateness, and significance of change in an environment are made with input from stakeholders and in consideration of their values....those decisions and their resulting interventions have social validity" (Scott, T., 2007, p.105). From the perspective of the school's macro system - children, teachers, staff, and administrators - the PAWS program was a socially valid success that enhanced a system that positively affected students' perceptions of recognition and accountability.

\section{Discussion}

The embedded correlational mixed method study model asks the question, "How does the qualitative data add to an understanding of the mechanisms in the correlational model?" (Creswell \& Plano Clark, p. 106). For this research, the qualitative and quantitative information came from the same population, and with a relatively large 
sample size. In both forms of data, the same questions were addressed, in that the survey completed by students asked about their understanding and appreciation of the same variables investigated through numerical statistical analysis.

Seemingly, the qualitative findings of positive response to the PAWS changes was at odds with the quantitative statistical results indicating no significant differences in student behavior across the two study years. When considering the two sets of data, it appeared that although the student body adopted the new procedures and was able to express understanding of both the PBIS target behaviors and the relationships between behavior and rewards, this knowledge did little to impact individual actions for fifty-six students that school year. The intellectual comprehension of the PAWS program and an appreciation for it, did not translate into improved behavior for a small percentage (11.26\%) of the students at this elementary school. In the PBIS literature, the directive is to look first at changing the environment, and then at changing instruction in order to improve behavior. The idea is that by eliminating the cause of problem behavior, that response becomes ineffective and unnecessary (Sugai \& Horner, 2002).

The findings of this research confirmed previous research done on the universal program of PBIS in that the percentages of responsiveness to the universal components mirrored the expected success rates for PBIS implementation (see Table 9). PBIS expects $80 \%-85 \%$ of students to have zero to one referral, $5 \%-10 \%$ to accumulate two to five referrals, and $1 \%-5 \%$ to have six or more in a year's time (Walker et al, 1996). 
Table 9 2008-2009 PAWS percentages of ODR per total population

\begin{tabular}{|c|c|c|}
\hline $0-1$ referral & $2-5$ referrals & $6+$ referrals \\
$88.74 \%$ & $7.62 \%$ & $3.64 \%$ \\
\hline
\end{tabular}

Given the greatly increased amount of contingent rewards instituted during the PAWS year, this suggests that the use of rewards to regulate behavior must include exploration of when they are not effective. A meta-analysis of 128 studies investigating the effect of rewards on intrinsic motivation revealed that under certain conditions, tangible rewards can have a negative impact on the internal drive and personal control necessary for growth.

"Although rewards can control people's behavior-indeed, that is presumably why they are so widely advocated-the primary negative effect of rewards is that they tend to forestall self-regulation. In other words, reward contingencies undermine people's taking responsibility for motivating or regulating themselves" (Deci, Koestner, \& Ryan, 1999, p.659).

\section{Implications}

Evaluation of the results of this study led to several responses by the studied school. The mobility rate was of concern, especially when paired with information about the effect of a sense of belonging on student behavior. Research shows that students who do not feel ownership in a school are more likely to rebel or misbehave than those who consider the school to be theirs. As cited in Koth, Bradshaw, and Leaf (2008), Osterman's findings indicated that a sense of ownership in a school's culture led students to be more compliant and better behaved in their classrooms. To better 
acclimate new students to the school and its PBIS framework, new students now meet with the school guidance counselor, who explains PAWS, and they are given a "passport" that promotes familiarity with the layout and personnel as they travel through the building collecting initials. In the upper grades, team building activities are part of the guidance lessons, and a modification of the Mix-It Up program (Teaching Tolerance.org, n.d.) takes place twice a month for grades four and five. Classroom PBIS lessons will be supplemented by videoed examples and non-examples of the target behaviors as portrayed by students to spur discussion and problem solving and better instruct the concepts of Be Safe, Be Responsible, Be Respectful and Be There.

Just over $40 \%(24 / 56)$ of the students who were given an office discipline referral during the 2008-2009 school year were students with an Individualized Education Plan (I.E.P.). The significance of this number is that it highlighted the need to focus on the possibility of academic causes behind some of the misbehavior. For some students, the structure of the curriculum and the pace of instruction reach beyond the frustration point, and so problem behavior becomes their only option.

One response to addressing student academic and behavioral challenges at this study school is through Instructional Consultation Teams (Rosenfield \& Gravios, 1996). Individual students are identified and referred. This in turn begins a process of problem solving between the ICT case manager and the classroom teacher. Planned interventions are tracked and data is used to direct instruction by drawing on best practices based on matching instruction to student knowledge and skills.

\section{Future Research}

As Cuccaro \& Geitner (2007) indicated in their article, more studies are needed that investigate the most effective ways to structured PBIS so that both total school- 
wide behavior and those of individuals can be improved. Additional research investigating ways to enhance the universal program so to decrease referrals and influence the behavior of children in the zero to one referral group should continue. Specific focus on the kinds of rewards and their relationship to intrinsic motivation is another area of research, specifically the use of informational rewards, as promoted by the research of Deci and Ryan, among many others (1999). Perhaps investigating the ages at which problem behaviors begin may help guide the selection of rewards and influence types of responses by schools to those with emerging concerns.

That this elementary school was located in a small urban setting with significant demographic concerns regarding student mobility and the number of children from single parent homes perhaps limits the findings' application to other schools with more stable families, or those located in either large cities or conversely in rural areas. Review of the demographics and student data indicated that of the fifty-six students with referrals under the PAWS system, ten were new to the school for that school year, seven arriving during the second semester. These students also were responsible for forty of the 262 referrals accumulated. Perhaps a school with a more stable population may see more benefit with the introduction of increased rewards on the office discipline referral rate. Replication of the increased universal components in a middle or high school setting may also yield different findings. Further research to evaluate the impact of outside factors on student behaviors and how to make significant change is a large area of need.

PBIS literature references use of additional interventions for those students with more intensive needs. Research into effectiveness of individualized procedures would be the next step for making a significant impact on office discipline referral numbers. 
That is the next step being taken at the school in this study. Deliberate targeting of students who do not respond to the universal program requires ideas that will be effective for both the attention seeking student and the one that is trying to escape a classroom environment made aversive by low levels of academic success.

Additionally, an area of interest that emerged as a result of my involvement in the collection and analysis of both the quantitative and qualitative data was the notable numbers of students experiencing behavioral difficulties that concurrently had IEP's developed for either academic or language delay/disorder remediation. As a speechlanguage pathologist, the number of children on my caseload who also were being processed through the office for discipline referrals was striking. Further research on correlations between language based deficits and behavioral challenges must occur to ensure the most effective management and assistance for these children. For these few but needy, the universal components clearly were insufficient to help them behave successfully. Investigations into the relationships between office discipline referrals and the presence of I.E.P.'s is beginning at the state level (C. Bradshaw, personal communication, October 6, 2009).

A common thread through all of these suggestions for further research is the realization that as successful as PBIS has been in helping schools use positive, proactive instruction and rewards to improve student behavior, there are still many avenues to explore. Ensuring all students the opportunity to gain the skill sets, attitudes, and behaviors that will lead to lifelong growth necessitates that teachers, administrators, students and researchers neither allow themselves to give up nor to be satisfied. 


\section{REFERENCES}

Ayllon, T. \& Azrin, N. (1968). The token economy. Meredith Corporation, New York.

Barrett, S. B., Bradshaw, C. P., Lewis-Palmer, T. (2008). Maryland statewide PBIS initiative: systems, evaluations, and next steps. Journal of Positive Behavior Interventions, 10(2), 105-114.

Bradshaw, C.P., Reinke, W.M., Brown, L.D., Bevans, K., \& Leaf, P. (2008).

Implementation of school-wide positive behavioral interventions and supports (PBIS) in elementary schools: Observations from a randomized trial. Education \& Treatment of Children, 31 (1), $1-26$.

Biglan, A. (1995). Translating what we know about the context of antisocial behavior into a lower prevalence of such behavior. Journal of Applied Behavior Analysis, 28, 479-492.

Bordens, K.S., \& Abbott, B. B. (2002). Research design and methods: a process approach. New York: McGraw Hill.

Carr, E. G., Dunlap, G., \& Horner, R.H., Koegel, R., Turnbull, A., Sailor, W., Anderson, J., Albin, R., Koegel, L., \& Fox, L. (2002). Positive behavior support: evolution of an applied science. Journal of Positive Behavior Interventions, 4(1), 4-17.

Chafouleas, S., Riley-Tillman,T., Sassu, K., LaFrance, M., \& Patwa, S. (2007). Daily behavior report cards: An investigation of the consistency of on-task data across raters and methods. Journal of Positive Behavior Interventions, 9 (1), 30-37. 
Charthouse Learning. (2007). Fish! for schools. Retrieved November 7, 2008, from: http://www2.charthouse.com/ffs/home.asp

CliffsNotes.com. Paired Difference t-Test. 29 Nov 2008 http://www.cliffsnotes.com/WileyCDA/CliffsReviewTopic/topicArticleld$\underline{25951, \text { articleld-25940.html }}$

Clonan, S.M., McDougal, J.L., Clark, K., Davison, S. (2007). Use of office discipline referrals in school-wide decision making: A practical example. Psychology in the Schools, 44(1), $19-27$.

Corr, G.R. (1998). Office of special education and rehabilitative services: assistance to states for the education on individuals with disabilities. Federal register, 63(148), 41369 - 41382. Retrieved August 24, 2009 from www.ed.gov/legistation/FedRegister/other/1998-3.

Cozby, P.C. (1981). Methods in behavioral research. Palo Alto, CA: Mayfield Publishing Company.

Creswell, J.W. \& Plano Clark, V.L. (2007). Designing and conducting mixed methods research. Thousand Oaks, CA: Sage Publications.

Cuccaro, C., \& Geitner, G. (2007). Lunch and recess: the "eye of the storm": using targeted interventions for students with behavioral problems. TEACHING Exceptional Children Plus, 3(4) Article 2. 
Deci, E.L., Koestner, R., Ryan, R.M. (1999). A meta-analytic review of experiments examining the effects of extrinsic rewards on intrinsic motivation. Psychological Bulletin, 125 (6), $627-668$.

Dunlap, G. \& Horner, R. (2006). Applied behavior analytic heritage of positive behavior supports. Journal of Positive Behavior Interventions, 8(1), 58-60.

Durand,V.M. \& Carr, E.G. (1985). Self-injurious behavior: Motivating conditions and guidelines for treatment. School Psychology Review, 14 (2), 171-176.

Durand, V.M. \& Rost, N. (2005). Does it matter who participates in our studies? A caution when interpreting the research on PBS. Journal of Positive Behavior Interventions, 7(3), 186-188.

Fabiano, G.A., Pelham, W.E., Karmazin, K., Kreher, J., Panahon, C., \& Carlson, C. (2008). A group contingency program to improve the behavior of elementary school students in a cafeteria. Behavior Modification, 32(1), 121-132.

Freeman, R., Eber, L., Anderson, C., Irvin, L., Horner, R., Bounds, M., Dunlap, G. (2006). Building inclusive school cultures using school-wide positive behavior support. Research and practice for persons with severe disabilities, 31(1), 4-17.

Gravetter, F.J., \& Wallnau, L.B. (2007). Statistics for the behavioral sciences. Belmont, CA: Thomas Wadsworth.

Greitemeyer, T., Kazemi, E. (2008). Asymmetrical consequences of behavioral change through reward and punishment. European Journal of Social Psychology, 38, 246259. 
Hawkin, L.S. \& Horner, R.H. (2003). Evaluation of a targeted group intervention within a school-wide system of behavioral support. Journal of Behavioral Education, 12(3), 225-240.

Hawkin, L.S., \& Johnston, S.S. (2007). Preventing severe problem behavior in young children: The behavior education program. Journal of Early and Intensive Behavior Intervention, 4(3). 599-613.

Horner, R.H., Todd, A.W., Lewis-Parker, T., Ivin, L., Sugai, G., \& Boland, J. (2004). School-wide evaluation tool (SET): a research instrument for assessing school-wide positive behavior support. Journal of Positive Behavior Interventions, 6(1), 3 - 12.

Hyman, I.A. \& Wise, J.H. (Eds.) (1979). Corporal punishment in American education: readings in history, practice and alternative. Philadelphia: Temple University Press.

Individuals with Disabilities Education Act. (2004). Retrieved August 24, 2009 from http://idea/ed/gov.

Irvin, L.K., \& Tobin, T. J. (2004). Validity of office discipline referral measures as induces of school-wide behavioral status and effects of school-wide behavior interventions. Journal of Positive Behavior Interventions, 6(3), 131-147.

Irvin, L.K., Horner, R.H., Ingram, K., Todd, A., Sugai, G., Sampson, N., \& Boland, J. (2006).Using office referral data for decision making about student behavior in elementary and middle schools. Journal of Positive Behavior Interventions, 8(1), 1023. 
Killu, K., Weber, K.P., Derby, K.M., Barretto, A. (2006). Behavior intervention planning and implementation of positive behavioral support plans: an examination of states' adherence to standards of practice. Journal of Positive Behavior Interventions, 8 (4), $195-200$.

Koth, C.W., Bradshaw, C.B., \& Leaf, P. L. (2008). A multilevel study of predictors of student perceptions of school climate: the effect of classroom-level factors. Journal of Educational Psychology, 100 (1), 96-104.

Larson, J. (1994). Violence prevention in schools: A review of selected programs and procedures. School Psychology Review, 23, 151-164.

LaVigna, G.W., \& Willis, T. D. (2005). Episodic severity: An overlooked dependent variable in application of behavior analysis to challenging behavior. Journal of Positive Behavior Interventions, 7(1), 47-54.

Long, N., Edwards, M. (1994). The use of a daily report card to address children's school behavior problems. Contemporary Education, 65(3), 152-156.

Losel, F. \& Beelmann, A. (2003). Effects of child skills training in preventing antisocial behavior: A systematic review of randomized evaluations. Annals of the American Academy of Political and Social Science, 587, 84-109.

Ludwig von Bertalanffy: passages from general systems theory. (n.d.). Retrieved October 13, 2008, from http://www.panarchy.org/vonbertalanffy/systems.1968.html

Lundberg, G. A. (1942). Social research: A study in methods of gathering data. New York: Greenwood Press, Publishers. 
May, Ard, Todd, Horner, Glasgow, Sugai, \& Sprague. (2008). School-wide information system (Version 4.21) [Online computer program]. http://swis.org

Messick, S. (1988). The once and future issues of validity: Assessing the meaning and consequences of measurement. In $\mathrm{H}$. Wainer \& $\mathrm{H}$. Braun (Eds.), Test validity (pp. 33-45). Hillsdale, N.J.: Erlbaum.

Metzler, C.W., Biglan, A., Rusby, J.C. \& Sprague, J. (2001). Evaluation of a comprehensive behavior management program to improve school-wide positive behavior supports. Education \& Treatment of Children, 24(4), 448-479.

Miles, M.B. \& Huberman, A.M. (1984). Drawing valid meaning from qualitative data: toward a shared craft. Educational Researcher, 13 (5), 20-30.

Missouri State Department of Elementary and Secondary Education, (2001). PBIS: Show me how technical bulletin. Retrieved October 7, 2008, from www/ertc.ed.gov/ERICDocs/data/ericdoc2sql/content_storage_01/0000019b/80/16/e f/3c.pdf

Mitchell, G. Bertalanffy's general system theory. Retrieved December 1, 2008, from http://www.trans4mind.com/mind-development/system.html

Mix It Up. (n.d.) Retrieved November 18, 2009 from http://www.tolerance.org/mix-it-up

Morgan, S.E., Reichert, T., \& Harrison, T.R. (2002). From Numbers to Words: Reporting Statistical Results for the Social Sciences. Boston: Allyn and Bacon. 
Nelson, R.J., Martella, R.M., \& Marchand-Martella, N. (2002). Maximizing student learning: The effects of a comprehensive school-based program for preventing behavior problems. Journal of Emotional and Behavioral Disorders, 10(3), 136-148.

National Technical Assistance Center on Positive Behavioral Interventions and Supports (PBIS). PBIS Network. Retrieved November 18, 2008, from: www.pbis.org/map.htm

Nelson, J. R., Gonzales, J. E., Epstein, M. H., \& Benner, G. J. (2003). Administrative discipline contacts: A review of the literature. Behavioral Disorders, (28), 249-281.

O'Leary, K. D., \& Drabman, R. (1971). Token reinforcement programs in the classroom: A review. Psychological Bulletin, 75, 379-398.

www.pbismaryland.org/initiative.htm. Retrieved October 3, 2008.

Perreault, W.D. \& Leigh, L.E. (1989). Reliability of nominal data based on qualitative judgments. Journal of Marketing Research, 26 (2), 133-148.

Riley-Tillman, T.C., Chafouleas, S.M., \& Briesch, A.M. (2007). A school practitioner's guide to using daily behavior report cards to monitor student behavior. Psychology in the Schools, 44(1), 77-89.

Rosenfield, S. A. \& Gravois, T. A. (1996). Instructional Consultation Teams, New York, Gilford Press.

Satcher, D. (1999). Executive summary youth violence: a report of the surgeon general. Retrieved November 7, 2008 from www.surgeongeneral.gov/library/youthviolence/summary.htm. 
School emergency forms 2008-2009 [Data file]. Cumberland, MD; West Side Elementary School.

Scott, T. (2007). Issues of personal dignity and social validity in schoolwide systems of positive behavior support. Journal of Positive Behavior Interventions, 9(2), 102-112.

Scott, T. (2006). Coaching PBS in school settings: tactics and data based decision making. Journal of Positive Behavior Interventions, 8(3), 165-173.

Sharpley, C.F. (1988). Effects of varying contingency and directness of rewards upon children's performance under implicit reward conditions. Journal of Experimental Child Psychology, 45(3),

Smrekar, C.E. \& Owns, D.E. (2003). It's a way of life for us: High mobility and high achievement in Department of Defense schools. The Journal of Negro Education, 72(1), 165-177.

Sprague, J., Sugai, G., Horner, R., \& Walker, H. (1999). Using office discipline referral data to evaluate school-wide discipline and violence prevention interventions. Oregon school study council bulletin, 42(2), Eugene, Oregon: University of Oregon, College of Education.

Sprague, J., Walker, H., Golly, A., White, K., Myers, D., \& Shannon, T. (2001). Translating research into effective practice: The effects of a universal staff and student intervention on indicators of discipline and school safety. Education and Treatment of Children, 24(4), 495-511.

Sugai, G., \& Horner, R. H. (2002). The evolution of discipline practices: school-wide 
positive behavior supports. Child \& Family Behavior Therapy, 24(1/2), 23-50.

Sugai, G., Horner, R. H., Dunlap, G., Hieneman, M., Nelson, C., Scott, T., Liaupsin, C., Sailor, W., Turnbull, A., Turnbull III, H., Wickham, D., Wilcox, B., \& Ruef, M. (2000). Applying positive behavior support and functional behavioral assessment in schools. Journal of Positive Behavior Interventions, 2(3), 131 - 143.

Sugai, G., Colvin, G, Hagan-Burke, S., \& Lewis-Palmer, T. (2001). Components and processes of school-wide discipline systems. Maryland Institute 2002 Positive Behavioral Interventions and supports; Maryland school-wide positive behavior support for all students: getting started team training. OSEP Center on positive behavioral interventions and supports: University of Oregon.

Sugai, G., Horner, R., Lewis-Palmer, T., Hagan-Burke, S., Todd, A., Tobin, T. (2001). Overview of school-wide positive behavior support. Maryland Institute 2002 Positive Behavioral Interventions and supports; Maryland school-wide positive behavior support for all students: getting started team training. OSEP Center on positive behavioral interventions and supports: University of Oregon.

Sugai, G., Horner, R. \& Todd, A. (2000). EBS Self-assessment survey, version 2.0, August 2003. Educational and Community Supports: University of Oregon. http://www.pbis.org/evaluation/evaluation tools.aspx Accessed September 20, 2009.

Taylor-Greene, S., Brown, D., Nelson, L., Longton, J., Gassman, T., Cohen, J., Swartz, J., Horner, R., Sugai, G., \& Hall, S. (1997). School-wide behavioral support: Starting the year off right. Journal of Behavioral Education, 7(1), 99-112. 
Torbert, W.R. (1972). Learning from Experience: Toward Consciousness. New York: Columbia University Press.

Turnbull, H.R., Wilcox, B., Stowe, M., Raper, C., Hedges, L. (2000). Public policy foundations for positive behavior intervention strategies and supports. Journal of Positive Behavior Interventions, 2(4), 218-230.

Tymchuk, A. J. (1971). Token economy and motivating environment for mildly retarded adolescent boys. Mental Retardation, 9 (6), 8.

United States Census. (2000). Retrieved October 21,2008 from http://factfinder.census.gov

U. S. Department of Education (2003). Special Education \& Rehabilitative Services Archived: A 25 year history of the IDEA. History Twenty-five years of progress in educating children with disabilities through IDEA. Retrieved November 7, 2008 from http://www.ed.gov/policy/speced/leg/idea/history.html

Walker, H.M., Hill, M., Horner, R.H., Sugai, G., Bullis, M., \& Sprague, J. (1996). Integrated approaches to preventing antisocial behavior patterns among school-age children and youth. Journal of Emotional and Behavioral Disorders, 4(4), 194-209.

West Side Elementary School. (2008). School improvement team (SIT) plan. Cumberland, MD: Author.

Withdrawal and enrollment lists 2007-2008[Data file]. Cumberland, MD; West Side Elementary School. 
Appendix A 
Matrix of Behavioral Expectations at ${ }^{*} \quad$ Flementary School Note: expectations listed under specific settings are in addition to those expected in all settings.

\begin{tabular}{|c|c|c|c|c|c|c|}
\hline All Settings & Classroom & Cafeteria & Halls/Restroom & Playground & Bus & Walker Line \\
\hline $\begin{array}{l}\text { Be Safe } \\
\text { Work, play, and travel } \\
\text { safely } \\
\text { Walk } \\
\text { Keep hands and feet to } \\
\text { self }\end{array}$ & $\begin{array}{l}\text { Use materials and } \\
\text { supplies safely } \\
\text { Chairs remain on } 4 \text { legs }\end{array}$ & $\begin{array}{l}\text { Stay in your seat } \\
\text { Sit in chairs correctly } \\
\text { (chair legs on floor) }\end{array}$ & $\begin{array}{l}\text { Walk on the right-hand } \\
\text { side } \\
\text { Obey stop signs }\end{array}$ & $\begin{array}{l}\text { Follow equipment rules } \\
\text { Never leave playground } \\
\text { w/o permission } \\
\text { Play in designated } \\
\text { areas }\end{array}$ & $\begin{array}{l}\text { Obey all bus staff } \\
\text { directions } \\
\text { Stay seated, facing } \\
\text { forward } \\
\text { Keep aisles clear } \\
\text { Do not throw items }\end{array}$ & $\begin{array}{l}\text { Stay with school staff } \\
\text { until released } \\
\text { Cross only at } \\
\text { crosswalks - trained } \\
\text { staff to assist }\end{array}$ \\
\hline $\begin{array}{l}\text { Be Respectful } \\
\text { Use respectful tone, } \\
\text { words, and behavior } \\
\text { Respect others' } \\
\text { belongings } \\
\text { Avoid disrupting others' } \\
\text { learning } \\
\text { Use problem-solving } \\
\text { skills } \\
\text { Accept consequences } \\
\text { without arguing or } \\
\text { complaining }\end{array}$ & $\begin{array}{l}\text { Use an inside voice } \\
\text { Listen when others } \\
\text { speak - Eyes on the } \\
\text { speaker } \\
\text { Raise hand } \\
\text { Sharpen pencils before } \\
\text { lessons begin }\end{array}$ & $\begin{array}{l}\text { Use "good manners" } \\
\text { Keep conversation } \\
\text { polite - use kind words } \\
\text { Use inside voice, talk } \\
\text { with people at own } \\
\text { table only }\end{array}$ & $\begin{array}{l}\text { Be silent in line } \\
\text { Maintain personal } \\
\text { space } \\
\text { Respect others' privacy } \\
\text { in restroom } \\
\text { Flush the toilet } \\
\text { Wash your hands } \\
\text { Use bathroom } \\
\text { equipment } \\
\text { appropriately }\end{array}$ & $\begin{array}{l}\text { Take turns, share } \\
\text { equipment } \\
\text { Follow rules on } \\
\text { playground equipment } \\
\text { Play safely. } \\
\text { Include others. } \\
\text { Return equipment to } \\
\text { proper place }\end{array}$ & $\begin{array}{l}\text { Keep conversation } \\
\text { polite } \\
\text { Use an inside voice } \\
\end{array}$ & $\begin{array}{l}\text { Obey instructions of } \\
\text { staff members assisting } \\
\text { walk lines }\end{array}$ \\
\hline $\begin{array}{l}\text { Be Responsible } \\
\text { Take care of self and } \\
\text { materials } \\
\text { Clean up after yourself } \\
\text { Follow directions } \\
\text { Be honest in words \& } \\
\text { actions } \\
\text { Accept consequences } \\
\text { without arguing or } \\
\text { zomplaining }\end{array}$ & $\begin{array}{l}\text { Do your best } \\
\text { Be prepared to learn }\end{array}$ & $\begin{array}{l}\text { Follow procedures for } \\
\text { entering, getting lunch, } \\
\text { and exiting } \\
\text { Raise your hand for } \\
\text { assistance }\end{array}$ & $\begin{array}{l}\text { Be in assigned } \\
\text { locations only-have a } \\
\text { pass if not with your } \\
\text { class } \\
\text { Use bathroom in an } \\
\text { appropriate and timely } \\
\text { manner } \\
\text { Turn off sink faucet } \\
\text { Throw trash in garbage } \\
\text { container }\end{array}$ & $\begin{array}{l}\text { Stop playing when the } \\
\text { whistle blows } \\
\text { Line up calmly and } \\
\text { quickly in the correct } \\
\text { line } \\
\text { Leave playground clean } \\
\text { Take care of equipment }\end{array}$ & $\begin{array}{l}\text { No food or drinks on } \\
\text { bus } \\
\text { Leave bus clean }\end{array}$ & $\begin{array}{l}\text { Travel designated walk } \\
\text { line routes only }\end{array}$ \\
\hline
\end{tabular}


Appendix B 


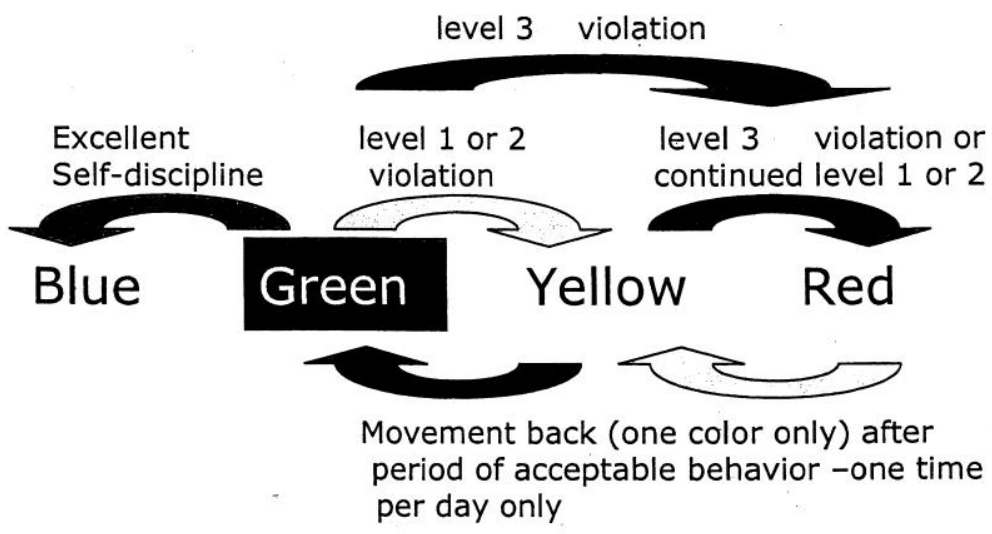

level 3 . violation

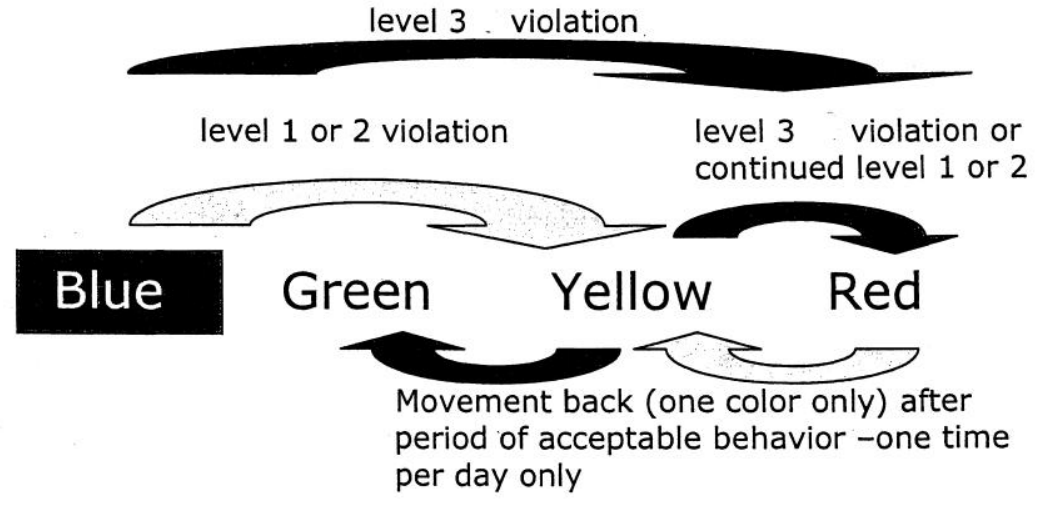


Appendix C 


\section{Elementary}

Office Discipline Referral Form

Name:

Date: Time:

Referring Staff

Grade:

Homeroom Teacher:

\begin{tabular}{|c|c|c|}
\hline Problem Behavior & Possible Motivation & Location \\
\hline $\begin{array}{ll} & \text { Fighting/physical aggression } \\
\square & \text { Harassment/Tease /Taunt } \\
\square & \text { Overt Defiance / Disrespect } \\
\square & \text { Insubordination } \\
\square & \text { Inappropriate Language and/or } \\
& \text { Profanity } \\
\square & \text { Disruption of Education } \\
\square & \text { Vandalism, Property Damage } \\
\square & \text { Other }\end{array}$ & $\begin{array}{ll} & \text { Obtain peer attention } \\
\square & \text { Obtain adult attention } \\
\square & \text { Obtain items - activities } \\
\square & \text { Avoid peers } \\
\square & \text { Avoid adult } \\
\square & \text { Avoid task - activity } \\
\square & \text { Other } \\
\end{array}$ & $\begin{array}{ll} & \text { Playground } \\
\text { 口 } & \text { Cafeteria } \\
\text { 口 } & \text { Hallway } \\
\text { a } & \text { Classroom } \\
\text { a } & \text { Resource Area } \\
\text { a } & \text { Bathroom } \\
\text { a } & \text { Arrival } \\
\text { a } & \text { Bus } \\
\text { a } & \text { Dismissal } \\
\text { a } & \text { Other }\end{array}$ \\
\hline
\end{tabular}

\begin{tabular}{|c|c|c|}
\hline Others Involved & Action Before Referral & Administrative Decision \\
\hline $\begin{array}{ll} & \text { None } \\
\square & \text { Peers } \\
\square & \text { Teacher } \\
\square & \text { Instructional } \\
& \text { Assistant } \\
\square & \text { Substitute } \\
\square & \text { Unknown } \\
\square & \text { Other }\end{array}$ & $\begin{array}{ll} & \text { Conference with student } \\
\square & \text { Phone Call Home } \\
\text { Date } \\
\text { Parent Conference } \\
\text { Date } \\
\square \text { Loss of Privilege } \\
\square & \text { In class intervention } \\
\text { a } & \text { Guidance Conference } \\
\square & \text { Previous referral to office } \\
\square & \text { Letter to Parent }\end{array}$ & 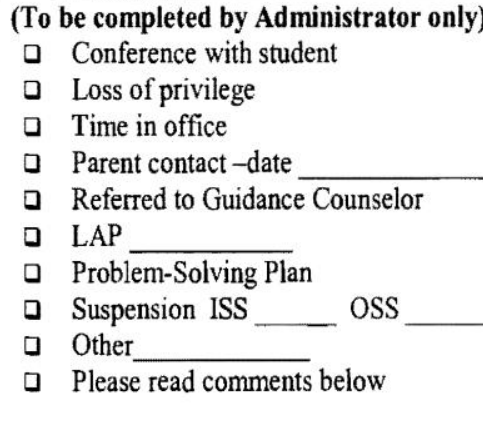 \\
\hline
\end{tabular}

Incident Description:

Administrative Decision:

\section{*PLEASE SIGN AND RETURN}

Administrator Signature: Date:

Parent Signature: Date: 
Appendix D 


\section{Board of Education of Allegany County}

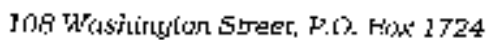

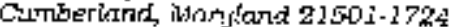

Trilephorte (301) $750-200 t$

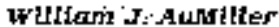

Sirifieriterickinl of $\$$ chopls

October 13,2008

To Whom It May Concern:

As Superinlendent of the Allegany County Public School System, I give permisslon for Lori Rumburg to conduct her dissertabion research study in the Allegany County Public Schnols.

I understand Ms. Rurnburg's research will investigate the irnpact of now PBIS stratogics implersented for the 2008-2009 school year in that scheol, ant will include referral data and attendance data analysis along with surveys completed by students and staff. I understand that no studentis will be identifiec in the group reporling of grade covol data. I also understand that this research is a requirement for completion of the doctorste of education degree in Curriculum and Education at West Virgiria University.

Sincerely,

.. $\mathrm{n}$

Williliam J. AuMiller, Ed.L.

Superintendenl of Schools 
Appendix E 


\section{West Side Elementary School \\ 425 Paca Street}

Cumberland, Maryland 21502

John W. Logsdon, Jr., Principal

Phone: $301-724-0340$

Scott Sisler, Administrative Assistant

Fax: 301-724-1651

October 6, 2008

To Whom It May Concern:

As principal of West Side Elementary, I am writing to give permission for Lorri Rumburg to conduct her dissertation research study at West Side Elementary in Cumberland, Maryland. I understand this research will investigate the impact of new PBIS strategies implemented the 2008-2009 school year in this school, and will include referral date and attendance data analysis along with surveys completed by students and staff. I understand that no students will be identified in the group reporting grade level data. I also understand that this research is a requirement for the completion of the Doctorate of Education degree in Curriculum and Education at West Virginia University.
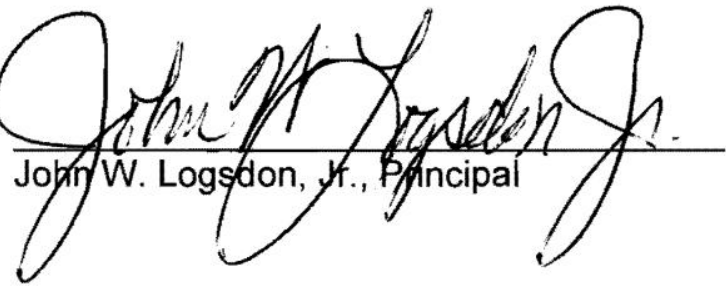
Appendix $\mathrm{F}$ 
Table 3 Office Discipline Referrals by Number of Students

\begin{tabular}{|l|c|c|c|c|c|c|c|}
\hline $\begin{array}{l}\text { School } \\
\text { Years }\end{array}$ & $\begin{array}{c}2002- \\
2003\end{array}$ & $\begin{array}{c}2003- \\
2004\end{array}$ & $\begin{array}{c}2004- \\
2005\end{array}$ & $\begin{array}{c}2005- \\
2006\end{array}$ & $\begin{array}{c}2006- \\
2007\end{array}$ & $\begin{array}{c}2007- \\
2008\end{array}$ & $\begin{array}{c}2008- \\
2009\end{array}$ \\
\hline 0 ODR & 208 & 217 & 245 & 231 & 203 & 272 & 246 \\
\hline 1 ODR & 47 & 31 & 27 & 22 & 27 & 19 & 22 \\
\hline $\begin{array}{l}2-5 \\
\text { ODR }\end{array}$ & 39 & 31 & 28 & 26 & 27 & 18 & 23 \\
\hline $\begin{array}{l}6 \text { or } \\
\text { more }\end{array}$ & 24 & 14 & 19 & 10 & 14 & 11 & 11 \\
\hline
\end{tabular}

Table 4 Office Discipline Referrals by Percentages of School Population

\begin{tabular}{|l|c|c|c|c|c|c|c|}
\hline $\begin{array}{l}\text { School } \\
\text { Years }\end{array}$ & $\begin{array}{c}2002- \\
2003\end{array}$ & $\begin{array}{c}2003- \\
2004\end{array}$ & $\begin{array}{c}2004- \\
2005\end{array}$ & $\begin{array}{c}2005- \\
2006\end{array}$ & $\begin{array}{c}2006- \\
2007\end{array}$ & $\begin{array}{c}2007- \\
2008\end{array}$ & $\begin{array}{c}2008- \\
2009\end{array}$ \\
\hline 0 ODR & 65.41 & 74.06 & 76.80 & 79.93 & 74.91 & 85.00 & 81.46 \\
\hline 1 ODR & 14.78 & 10.58 & 8.46 & 7.61 & 9.96 & 5.94 & 7.28 \\
\hline $\begin{array}{l}2-5 \\
\text { ODR }\end{array}$ & 12.26 & 10.58 & 8.78 & 9.00 & 9.96 & 5.63 & 7.62 \\
\hline $\begin{array}{l}6 \text { or } \\
\text { more }\end{array}$ & 7.55 & 4.78 & 5.96 & 3.46 & 5.17 & 3.44 & 3.64 \\
\hline
\end{tabular}


Appendix G 


\section{SCHOOL-WIDE SYSTEMS}

\begin{tabular}{|c|c|c|c|c|c|c|}
\hline \multicolumn{3}{|c|}{ Current Status } & \multirow{2}{*}{$\begin{array}{l}\text { Feature } \\
\text { School-wide is defined as involving all } \\
\text { students, all staff, \& all settings. }\end{array}$} & \multicolumn{3}{|c|}{ Priority for Improvement } \\
\hline $\begin{array}{l}\ln \\
\text { Place }\end{array}$ & $\begin{array}{l}\text { Partial } \\
\text { in } \\
\text { Place }\end{array}$ & $\begin{array}{l}\text { Not in } \\
\text { Place }\end{array}$ & & High & Med & Low \\
\hline & & & $\begin{array}{l}\text { 1. A small number (e.g. } 3-5 \text { ) of positively \& clearly } \\
\text { stated student expectations or rules are defined. }\end{array}$ & & & \\
\hline & & & 2. Expected student behaviors are taught directly. & & & \\
\hline & & & $\begin{array}{l}\text { 3. Expected student behaviors are rewarded } \\
\text { regularly. }\end{array}$ & & & \\
\hline & & & $\begin{array}{l}\text { 4. Problem behaviors (failure to meet expected } \\
\text { student behaviors) are defined clearly. }\end{array}$ & & & \\
\hline & & & $\begin{array}{l}\text { 5. Consequences for problem behaviors are } \\
\text { defined clearly. }\end{array}$ & & & \\
\hline & & & $\begin{array}{l}\text { 6. Distinctions between office v. classroom } \\
\text { managed problem behaviors are clear. }\end{array}$ & & & \\
\hline & & & $\begin{array}{l}\text { 7. Options exist to allow classroom instruction to } \\
\text { continue when problem behavior occurs. }\end{array}$ & & & \\
\hline & & & $\begin{array}{l}\text { 8.Procedures are in place to address } \\
\text { emergency/dangerous situations. }\end{array}$ & & & \\
\hline & & & $\begin{array}{l}\text { 9. A team exists for behavior support planning \& } \\
\text { problem solving. }\end{array}$ & & & \\
\hline & & & $\begin{array}{l}\text { 10. School administrator is an active participant } \\
\text { on the behavior support team. }\end{array}$ & & & \\
\hline & & & $\begin{array}{l}\text { 11. Data on problem behavior patterns are } \\
\text { collected and summarized within an on-going } \\
\text { system. }\end{array}$ & & & \\
\hline & & & $\begin{array}{l}\text { 12. Patterns of student problem behavior are } \\
\text { reported to teams and faculty for active decision- } \\
\text { making on a regular basis (e.g. monthly). }\end{array}$ & & & \\
\hline & & & $\begin{array}{l}\text { 13. School has formal strategies for informing } \\
\text { families about expected student behaviors at } \\
\text { school. }\end{array}$ & & & \\
\hline & & & $\begin{array}{l}\text { 14. Booster training activities for students are } \\
\text { developed, modified, \& conducted based on } \\
\text { school data. }\end{array}$ & & & \\
\hline & & & $\begin{array}{l}\text { 15. School-wide behavior support team has a } \\
\text { budget for (a) teaching students, (b) on-going } \\
\text { rewards, and (c) annual staff planning. }\end{array}$ & & & \\
\hline & & & $\begin{array}{l}\text { 16. All staff are involved directly and/or indirectly } \\
\text { in school-wide interventions. }\end{array}$ & & & \\
\hline
\end{tabular}

EBS Self-Assessment Survey version 2.0 August 2003

○2000 Sugai, Horner \& Todd, Educational and Community Supports

University of Oregon 


\begin{tabular}{|c|c|l|l|l|l|l|}
\hline \multicolumn{2}{|c|}{ Current Status } & \multicolumn{1}{c|}{ Feature } & \multicolumn{2}{c|}{ Priority for Improvement } \\
\hline $\begin{array}{c}\text { In } \\
\text { Place }\end{array}$ & $\begin{array}{c}\text { Partial } \\
\text { in } \\
\text { Place }\end{array}$ & $\begin{array}{c}\text { Not in } \\
\text { Place }\end{array}$ & $\begin{array}{l}\text { School-wide is defined as involving all } \\
\text { students, all staff, \& all settings. }\end{array}$ & High & Med & Low \\
\hline & & $\begin{array}{l}\text { 17. The school team has access to on-going } \\
\text { training and support from district personnel. }\end{array}$ & & & \\
\hline & $\begin{array}{l}\text { 18. The school is required by the district to report } \\
\text { on the social climate, discipline level or student } \\
\text { behavior at least annually. }\end{array}$ & & & \\
\hline
\end{tabular}

Name of School

Date

EBS Self-Assessment Survey version 2.0 August 2003

(C2000 Sugai, Horner \& Todd, Educational and Community Supports

University of Oregon

Revised 08/27/03 DP

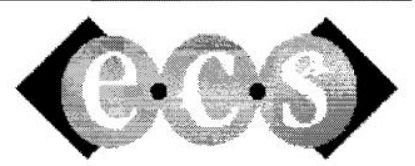




\section{NONCLASSROOM SETTING SYSTEMS}

\begin{tabular}{|c|c|c|c|c|c|c|}
\hline \multicolumn{3}{|c|}{ Current Status } & \multirow{2}{*}{$\begin{array}{l}\text { Feature } \\
\text { Non-classroom settings are defined as particular } \\
\text { times or places where supervision is emphasized } \\
\text { (e.g., hallways, cafeteria, playground, bus). }\end{array}$} & \multicolumn{3}{|c|}{ Priority for Improvement } \\
\hline $\begin{array}{l}\ln \\
\text { Place }\end{array}$ & $\begin{array}{l}\text { Partial } \\
\text { in } \\
\text { Place }\end{array}$ & $\begin{array}{l}\text { Not in } \\
\text { Place }\end{array}$ & & High & Med & Low \\
\hline & & & $\begin{array}{l}\text { 1. School-wide expected student behaviors apply to } \\
\text { non-classroom settings. }\end{array}$ & & & \\
\hline & & & $\begin{array}{l}\text { 2. School-wide expected student behaviors are taught } \\
\text { in non-classroom settings. }\end{array}$ & & & \\
\hline & & & $\begin{array}{l}\text { 3. Supervisors actively supervise (move, scan, \& } \\
\text { interact) students in non-classroom settings. }\end{array}$ & & & \\
\hline & & & $\begin{array}{l}\text { 4. Rewards exist for meeting expected student } \\
\text { behaviors in non-classroom settings. }\end{array}$ & & & \\
\hline & & & $\begin{array}{l}\text { 5. Physical/architectural features are modified to limit } \\
\text { (a) unsupervised settings, (b) unclear traffic patterns, } \\
\text { and (c) inappropriate access to \& exit from school } \\
\text { grounds. }\end{array}$ & & & \\
\hline & & & $\begin{array}{l}\text { 6. Scheduling of student movement ensures } \\
\text { appropriate numbers of students in non-classroom } \\
\text { spaces. }\end{array}$ & & & \\
\hline & & & $\begin{array}{l}\text { 7. Staff receives regular opportunities for developing } \\
\text { and improving active supervision skills. }\end{array}$ & & & \\
\hline & & & $\begin{array}{l}\text { 8. Status of student behavior and management } \\
\text { practices are evaluated quarterly from data. }\end{array}$ & & & \\
\hline & & & $\begin{array}{l}\text { 9. All staff are involved directly or indirectly in } \\
\text { management of non-classroom settings. }\end{array}$ & & & \\
\hline
\end{tabular}

Name of School

Date

EBS Self-Assessment Survey version 2.0 August 2003

(๑)2000 Sugai, Horner \& Todd, Educational and Community Supports University of Oregon

Revised 08/27/03 DP

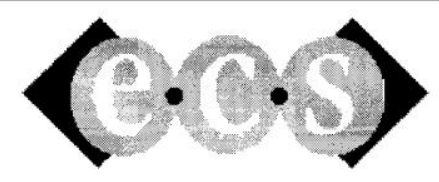


INDIVIDUAL STUDENT SYSTEMS

\begin{tabular}{|c|c|c|c|c|c|c|}
\hline \multicolumn{3}{|c|}{ Current Status } & \multirow{2}{*}{$\begin{array}{l}\text { Feature } \\
\text { Individual student systems are defined as specific } \\
\text { supports for students who engage in chronic problem } \\
\text { behaviors }(1 \%-7 \% \text { of enrollment) }\end{array}$} & \multicolumn{3}{|c|}{ Priority for Improvement } \\
\hline $\begin{array}{l}\ln \\
\text { Place }\end{array}$ & $\begin{array}{l}\text { Partial } \\
\text { in } \\
\text { Place }\end{array}$ & $\begin{array}{l}\text { Not in } \\
\text { Place }\end{array}$ & & High & Med & Low \\
\hline & & & $\begin{array}{l}\text { 1. Assessments are conducted regularly to identify } \\
\text { students with chronic problem behaviors. }\end{array}$ & & & \\
\hline & & & $\begin{array}{l}\text { 2. A simple process exists for teachers to request } \\
\text { assistance. }\end{array}$ & & & \\
\hline & & & $\begin{array}{l}\text { 3. A behavior support team responds promptly (within } \\
2 \text { working days) to students who present chronic } \\
\text { problem behaviors. }\end{array}$ & & & \\
\hline & & & $\begin{array}{l}\text { 4. Behavioral support team includes an individual } \\
\text { skilled at conducting functional behavioral } \\
\text { assessment. }\end{array}$ & & & \\
\hline & & & $\begin{array}{l}\text { 5. Local resources are used to conduct functional } \\
\text { assessment-based behavior support planning ( } 10 \\
\mathrm{hrs} / \text { week/student). }\end{array}$ & & & \\
\hline & & & $\begin{array}{l}\text { 6. Significant family } \& / o r \text { community members are } \\
\text { involved when appropriate \& possible. }\end{array}$ & & & \\
\hline & & & $\begin{array}{l}\text { 7. School includes formal opportunities for families to } \\
\text { receive training on behavioral support/positive } \\
\text { parenting strategies. }\end{array}$ & & & \\
\hline & & & $\begin{array}{l}\text { 8. Behavior is monitored \& feedback provided } \\
\text { regularly to the behavior support team \& relevant staff. }\end{array}$ & & & \\
\hline
\end{tabular}

Name of School

Date

EBS Self-Assessment Survey version 2.0 August 2003

(c)2000 Sugai, Horner \& Todd, Educational and Community Supports

University of Oregon

Revised 08/27/03 DP

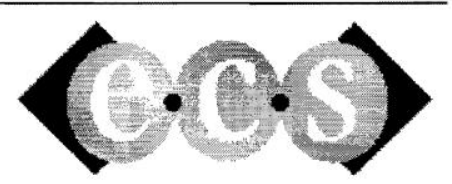


Appendix $\mathrm{H}$ 
How do you feel about...

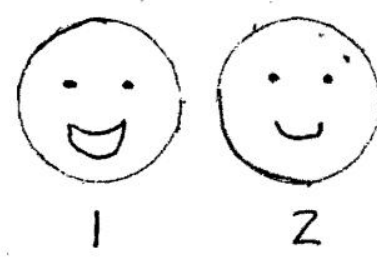
Great Good
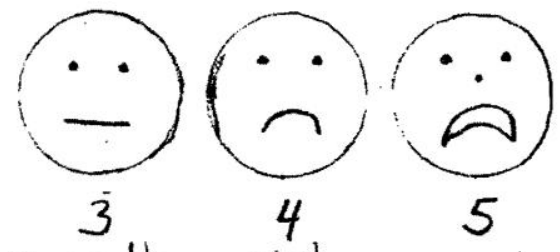
Doesn't Not Motter Good

(1... filling in PAWS calendar

Q... having the C-ATtitude bax in your room

(3)... getting PAWS coupons

(1)... buying from the Treasure Tower

Q... having names drawn in your room

Q... adding up points and PAW coupons

I earned a coin because

I got PAW coupons because

The colored PAWS on my calendar tell me

What I like about PAWs

What I don't like about PAWS 
Appendix I 


\section{C-ATitude}

Be Responsible, Be Respectful, Be Safe BE THERE

Name

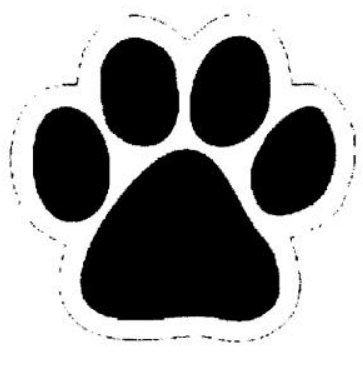

\begin{tabular}{|l|l|l|}
\hline & Tally marks & Total \\
\hline Blue & & \\
\hline Green & & \\
\hline Yellow & & \\
\hline Red & & \\
\hline PAW Prints & & \\
\hline
\end{tabular}

Month

Which color had the most?

Which color had the least?

What could you do to earn more PAW prints next month? 
Appendix $\mathrm{J}$ 
Table 2 Comparative Office Discipline Referrals (ODR) for school year 2007-2008 (Key) and 2008-2009 (PAW).

\begin{tabular}{|c|c|c|c|c|}
\hline Grade & Gender & Student & $\begin{array}{l}\text { Key } \\
\text { ODR }\end{array}$ & $\begin{array}{l}\text { PAW } \\
\text { ODR }\end{array}$ \\
\hline 5 & 1 & 117000 & 1 & 0 \\
\hline 4 & 0 & 1959723 & 1 & 0 \\
\hline 5 & 1 & 360469 & 3 & 0 \\
\hline 2 & 1 & 1220168 & 4 & 0 \\
\hline 2 & 1 & 1724458 & 5 & 0 \\
\hline 4 & 1 & 1140542 & 0 & 1 \\
\hline 3 & 1 & 1177350 & 0 & 1 \\
\hline 5 & 0 & 231599 & 0 & 1 \\
\hline 5 & 0 & 2391646 & 0 & 1 \\
\hline 5 & 0 & 2536944 & 0 & 1 \\
\hline 5 & 0 & 2536952 & 0 & 1 \\
\hline 4 & 1 & 2576011 & 0 & 1 \\
\hline 1 & 1 & 2605622 & 0 & 1 \\
\hline 2 & 1 & 2605073 & 0 & 1 \\
\hline 2 & 1 & 1057688 & 8 & 2 \\
\hline 2 & 1 & 1349522 & 2 & 2 \\
\hline 5 & 1 & 209401 & 2 & 2 \\
\hline 5 & 1 & 2306055 & 0 & 2 \\
\hline 5 & 0 & 2505294 & 0 & 2 \\
\hline 2 & 1 & 2505348 & 0 & 2 \\
\hline 5 & 1 & 1220167 & 1 & 3 \\
\hline 5 & 1 & 1724403 & 1 & 3 \\
\hline 3 & 0 & 2569031 & 0 & 3 \\
\hline 5 & 1 & 1921564 & 1 & 4 \\
\hline 5 & 1 & 455207 & 4 & 4 \\
\hline 5 & 1 & 1141649 & 0 & 4 \\
\hline 4 & 1 & 2291979 & 0 & 4 \\
\hline 2 & 1 & 1919254 & 4 & 4 \\
\hline 5 & 1 & 401310 & 15 & 14 \\
\hline 5 & 0 & 320790 & 1 & 19 \\
\hline 92 & 1 & 1724267 & 4 & 23 \\
\hline
\end{tabular}

